\title{
Maternal alcohol binge drinking induces persistent neuroinflammation associated with myelin damage and behavioral dysfunctions in offspring mice
}

Lídia Cantacorps ${ }^{1}$, Silvia Alfonso-Loeches ${ }^{3}$, Maria Moscoso-Castro ${ }^{1}$, Javier Cuitavi ${ }^{3}$, Irene Gracia-Rubio ${ }^{1}$, Raúl López-Arnau ${ }^{4}$, Elena Escubedo ${ }^{4}$, Consuelo Guerri ${ }^{3}$, Olga Valverde ${ }^{1,2^{*}}$

${ }^{1}$ Neurobiology of Behavior Research Group (GReNeC-NeuroBio), Department of Experimental and Health Sciences, Universitat Pompeu Fabra, Barcelona, Spain.

${ }^{2}$ Neuroscience Research Programme. IMIM-Hospital del Mar Research Institute, Barcelona, Spain.

${ }^{3}$ Molecular and Cellular Pathology of Alcohol, Prince Felipe Research Center, Eduardo Primo Yúfera 3, 46012, Valencia, Spain.

${ }^{4}$ Department of Pharmacology, Toxicology and Medicinal Chemistry (Pharmacology Section) and Institute of Biomedicine (IBUB), Faculty of Pharmacy, University of Barcelona, Barcelona, Spain.

\section{*Corresponding author:}

Olga Valverde MD PhD

Grup de Recerca en Neurobiologia del Comportament (GReNeC).

Departament de Ciències Experimentals i de la Salut. Universitat Pompeu Fabra.

Parc de Recerca Biomèdica de Barcelona. Dr. Aiguader, 88. 08003- Barcelona. Spain.

Tel. +34933160867

olga.valverde@upf.edu

Running title: Neuroinflammation in offspring after maternal alcohol binge drinking 


\section{Abbreviations:}

- AP-1: Activator protein-1

- BAC: Blood alcohol concentration

- CNS: Central nervous system

- DID: Drinking in the dark

- FAS: Fetal Alcohol Syndrome

- FASD: Fetal alcohol spectrum disorders

- GAPDH: Glyceraldehyde 3-phosphate dehydrogenase

- GC-FID: Gas Chromatography-Flame Ionization Detector

- HMGB1: High-mobility group box 1

- HPC: Hippocampus

- IL: Interleukin

- LMNA: Lamin A/C

- MAG: Myelin-associated glycoprotein

- MBP: Myelin basic protein

- MIA: Maternal immune activation

- MYRF: Myelin Regulatory Factor

- NF-кB p65: Nuclear factor-kappa B p65 subunit

- NLRP3: Nod-like receptor protein 3

- PAE: Prenatal alcohol-exposed

- PD: Postnatal day

- PFC: Prefrontal cortex

- PLAE: Prenatal and lactation alcohol-exposed

- PLP: Myelin proteolipid protein

- ROS: Reactive oxygen species

- TLR: Toll-like receptor

- VLN: Vinculin

\section{Highlights:}

- Maternal alcohol binge drinking induces neuroinflammation in the offspring.

- Motor coordination impairments are found in early alcohol-exposed mice.

- Prenatal and early postnatal alcohol exposure induces cognitive deficits.

- Myelin damage is found in mice developmentally exposed to alcohol.

Keywords: alcohol binge drinking, development, neuroinflammation, behavioral dysfunction, neurodegeneration, myelin. 


\begin{abstract}
Binge alcohol drinking is increasing among the young adult population and its consumption during pregnancy can be deleterious for the fetal development. Maternal alcohol consumption leads to a wide range of long-lasting morphological and behavioral deficiencies known as fetal alcohol spectrum disorders (FASD), associated with neurodevelopmental disabilities. We sought to test the effects of alcohol on neuroimmune system activation and its potential relation with alcohol-induced neurodevelopmental and neurobehavioral persistent effects in offspring after maternal alcohol binge drinking during the prenatal period, or in combination with lactation. Pregnant C57BL/6J female mice underwent a procedure for binge alcohol drinking either during the gestation or both the gestation and lactation periods. Subsequently, adult male offspring were assessed for cognitive functions and motor coordination. Early alcohol exposure induced motor coordination impairments in the rotarod test. Object recognition test was not significantly affected by maternal binge alcohol drinking, but Y-maze performance was impaired in pre- and early postnatal alcohol-exposed mice. The behavioral effects were associated with an up-regulation of pro-inflammatory signaling (Toll-like receptor 4, Nuclear factor-kappa B p65, Nod-like receptor protein 3, caspase-1, and Interleukin-1 $\beta$ ), gliosis, neuronal cell death and a reduction in several structural myelin proteins (Myelin-associated glycoprotein, Myelin basic protein, Myelin proteolipid protein and Myelin Regulatory Factor) in both the prefrontal cortex and hippocampus of adult mice developmentally exposed to alcohol. Altogether, our results reveal that neuroinflammation induced by maternal binge-like alcohol consumption could contribute to myelin damage and apoptotic neurodegeneration in the offspring's brain, effects that might underlie the persistent cognitive and behavioral impairments observed in FASD.
\end{abstract}




\section{Introduction}

The developing central nervous system (CNS) is particularly vulnerable to the toxic effects of alcohol (Alfonso-Loeches and Guerri, 2011; Andersen, 2003). Indeed, alcohol exposure in utero can lead to a wide range of long-lasting physical, cognitive and neurobehavioral anomalies in offspring collectively known as fetal alcohol spectrum disorders (FASD) (Dörrie et al., 2014; Jacobson and Jacobson, 2002; Larkby et al., 1997; Sokol et al., 2003), being Fetal Alcohol Syndrome (FAS) the most severe form of the FASD spectrum, characterized by gross skeletal and craniofacial abnormalities and severe CNS alterations (Jones and Smith, 1973). Despite its preventability, FASD remains a leading cause of neurodevelopmental disability affecting from 2 to 5\% of the population in the United States and western Europe (CDC, 2016; May et al., 2014). Some studies have shown that heavy episodic drinking throughout pregnancy is associated with severe risks of neurodegeneration and cognitive damage (Flak et al., 2014; Saito et al., 2016). However, there exist some discrepancies in the literature within the studies addressing the neurobiological consequences of alcohol bingeing during critical periods of brain development. These differences could be due to the developmental timing of alcohol exposure which markedly influences the neurobehavioral dysfunction outcome since each brain region has its own sensitive developmental period (Alfonso-Loeches and Guerri, 2011; Sadrian et al., 2014). In addition, other biological and environmental factors can influence the extent of alcoholinduced damage in the developing brain, such as the dose and the exposure pattern of alcohol, the mother's and fetus's genetic background, maternal nutrition and synergistic reactions with other drugs.

The molecular mechanisms of alcohol-induced neuroteratogenesis are complex, and different studies have demonstrated that alcohol disrupts the formation of the developing CNS interfering with several of the molecular, biochemical and cellular events that are required for neurodevelopment (Alfonso-Loeches and Guerri, 2011; Guerri et al., 2009; Most et al., 2014) leading to long-term cognitive and behavioral dysfunction. Recent studies have shown that alcohol can activate the innate neuroimmune system, contributing to brain damage and neurodegeneration in adults and adolescents (Crews et al., 2015; Montesinos et al., 2016a). These studies demonstrate that alcohol intake stimulates brain immune cells, microglia and astrocytes (Alfonso-Loeches et al., 2010; Fernandez-Lizarbe et al., 2009), by activating innate immune receptors, Toll-like receptors (TLRs) and NOD-like receptors, triggering signaling pathways that culminate in the production of pro-inflammatory cytokines and chemokines, leading to neuroinflammation, myelin alterations and neural damage (Alfonso-Loeches et al., 2012, 2010; Crews et al., 2015; Montesinos et al., 2016, 2015). However, although the role of neuroimmune system activation in the pathogenesis of FAS has been scarcely addressed, some recent studies have shown that alcohol exposure during the neonatal period causes microglial activation and the release of cytokines, suggesting an activation of the immune response (Drew and Kane, 2014; Topper et al., 2015). Interestingly, maternal immune activation (MIA) and inflammation during fetal and neonatal life also affect critical phases of brain development, and contribute to the development of neurological and mental disorders (see revs. Hagberg et al., 2015,2012 ) through a mechanism involving the activation of TLRs (Hagberg et al., 2015).

Therefore, the present study aims to evaluate the effects of alcohol on neuroimmune-related biomarkers in offspring from dams exposed to alcohol bingeing during gestation with and without lactation. To our knowledge, this is the first study assessing the effects of prenatal and 
lactational binge alcohol exposure using an animal model of voluntary maternal binge-like alcohol consumption, since in most of the previous studies, an ad libitum oral access, an inhalation or a parenteral route of alcohol administration was used at different time points of gestation (Patten et al., 2014). In addition, the molecular alterations induced by fetal and postnatal alcohol exposure were studied, especially those related to the neuroimmune response and its relation to myelination processes and neural damage in specific brain areas, such as the prefrontal cortex (PFC) and hippocampus (HPC) of mice exposed to binge alcohol consumption during early development, which could contribute to the behavioral outcome.

We have to strength that the experimental model used in the present study models a realistic human situation. Furthermore, we extended alcohol exposure to weaning, as most mothers who drink during pregnancy continue to do so when breastfeeding, thus transferring alcohol to infants via their milk (Haastrup et al., 2014). In addition, the first 10 postnatal days in rodents are approximately equivalent to the third human gestational trimester, covering then the total gestational period human-equivalent (Alfonso-Loeches and Guerri, 2011; Patten et al., 2014). In order to reproduce an episodic pattern of excessive alcohol drinking during pregnancy and lactation periods, we exposed pregnant and nursing C57BL/6J female mice to an alcohol solution using the drinking-in-the-dark (DID) test paradigm (Rhodes et al., 2005), proposed as a useful binge drinking model of FASD (Boehm et al., 2008). Subsequently, male offspring were assessed for their cognitive and motor function at adulthood. Motor coordination was evaluated by means of the rotarod test. Working and recognition memory were assessed using the Y-maze and the object recognition test, respectively. 


\section{Materials and methods}

\subsection{Animals}

Male and female C57BL/6J inbred mice were purchased from Charles River (Barcelona, Spain) and shipped to our animal facility (UBIOMEX, PRBB) to be used as breeders. Animals were 12 weeks old at the start of the breeding and were individually housed in standard cages in a temperature- $\left(21^{\circ} \pm 1{ }^{\circ} \mathrm{C}\right)$, humidity- $(55 \% \pm 10 \%)$, and light-cycle-controlled room. Lighting was maintained on a 12-hour reverse light-dark cycle with lights turned off between 08:00 and 20:00. Mice were allowed to acclimatize to the new environmental conditions for at least one week prior to experimentation, which took place during the dark phase under a dim red light. After successful mating, pregnant females were observed daily for parturition. For each litter, the date of birth was designated as postnatal day (PD) 0 . Pups remained with their mothers for 21 days and were then weaned (PD21). After weaning, male offspring were housed in groups of 4. Food and water were available ad libitum except when water was substituted for alcohol according to DID procedure and during behavioral testing of the offspring. Every effort was made to minimize the number of animals used and their suffering. All animal care and experimental procedures were conducted in accordance with the European Communities Directive 86/609/EEC regulating animal research and were approved by the local ethics committee (CEEA-PRBB).

\subsection{Drugs}

Ethyl alcohol was purchased from Merck Chemicals (Darmstadt, Germany) and diluted in tap water in order to obtain a $20 \%(\mathrm{v} / \mathrm{v})$ alcohol solution.

\subsection{Drinking-in-the-dark test}

This procedure was conducted as previously reported with minor modifications (Esteve-Arenys et al., 2017; Rhodes et al., 2005), starting two days after mating. Pregnant females were randomly assigned to two groups: alcohol and water-exposed (control). Briefly, the food was removed and the water bottles were replaced with 10-ml graduated cylinders fitted with sipper tubes containing either $20 \%(\mathrm{v} / \mathrm{v})$ alcohol in tap water or only tap water $3 \mathrm{~h}$ after the lighting was turned off. Following a $2 \mathrm{~h}$-access period, individual intake was recorded and food and water bottles were returned to the home cage. During this time, the mice were individually housed and each corresponding male breeding pair was removed from the home cage for the DID procedure. This procedure was repeated on days 2 and 3 and fresh fluids were provided each day (from Monday to Wednesday). On day 4 (Thursday), alcohol or water cylinders were left for $4 \mathrm{~h}$ and fluid intakes were recorded. Two empty control cages (water and alcohol) were placed in the rack to measure general liquid loss (leakage/evaporation) and drip values were subtracted from the drinking values. Fluid intakes ( $\mathrm{g} / \mathrm{kg}$ body weight) were calculated on the basis of average 2-day body weight values, as dams were weighed at 2-day intervals (Mondays and Wednesdays). This procedure was maintained throughout 3-week gestation and/or 3-week lactation periods. Food and water consumption during ad libitum periods was measured in both pregnant and nursing female mice.

\subsection{Blood alcohol concentration analysis}

Blood samples were collected from the submandibular vein of the female mice immediately after the final alcohol intake session ( $4^{\text {th }}$ day of third week). Blood samples were placed on ice 
for slow coagulation and were centrifuged at $10,000 \mathrm{xg}$ for $40 \mathrm{~min}$ at $4^{\circ} \mathrm{C}$ to obtain cell-free plasma, which was stored at $-80^{\circ} \mathrm{C}$ until the alcohol quantification analysis was performed. $5 \mu 1$ aliquots of each sample were transferred to sample microvials, combined with $5 \mu 1$ of internal standard solution $\left(0.2 \mathrm{~g} / \mathrm{l}\right.$ isopropanol) and placed in a water bath at $50^{\circ} \mathrm{C}$ for $5 \mathrm{~min}$. Then, $1 \mathrm{ml}$ of the headspace gas was injected manually with a Hamilton syringe into the gas chromatograph (Agilent 7890A GC-system) equipped with a flame ionization detector (GC-FID). Alcohol and internal standard were separated on a capillary column (Supelcowax-10®, 30m x $250 \mu \mathrm{m}$ x $0.25 \mu \mathrm{m}$ ) using helium as a carrier gas at a constant flow rate of $2.0 \mathrm{ml} / \mathrm{min}$ (split ratio $20: 1$ ). The column oven temperature was isothermal at $55^{\circ} \mathrm{C}$ and the injector and the FID system were set at 150 and $200^{\circ} \mathrm{C}$, respectively. Alcohol concentrations were quantified from linear standard curves $(10-200 \mathrm{mg} / \mathrm{dl}$ alcohol $)$ using the peak area ratios of alcohol to the internal standard using Agilent Chemstation software.

\subsection{Neonatal offspring assessment}

Litters were left undisturbed until PD5, when litter size was determined. The weights of the entire litter were collected on PD5 and PD21 and average pup weight was determined by dividing the total litter weight by the number of pups present in each litter as previously described (Brady et al., 2012). Postnatal mortality was calculated as [( $\mathrm{n}^{\circ}$ of pups on PD0- $\mathrm{n}^{\circ}$ of pups on PD5) $/ \mathrm{n}^{\circ}$ of pups on PD0] x 100. No significant between-group differences were found in any of the measured parameters (data not shown).

\subsection{Rotarod}

Late adolescent mice (PD48) were trained at a fixed speed $(4 \mathrm{rpm})$ on the accelerating rotarod apparatus (five-line accelerating rotarod; LE 8200, Panlab s.l.u, Barcelona, Spain) as previously reported (Bilkei-Gorzo et al., 2005; Moscoso-Castro et al., 2016). The rotarod accelerated from 4 to $40 \mathrm{rpm}$ over $2 \mathrm{~min}$. Motor coordination was measured in a session made up of ten consecutive trials interleaved by 30 -s breaks. The mean of rpm achieved before falling in the last four trials was averaged as a measure of motor coordination.

\subsection{Spontaneous alternation $Y$-maze test}

Adult mice (PD60) were assessed for spatial working memory as previously reported (Arai et al., 2001). Briefly, mice were placed in the center of a Y-shaped maze with the two equal arms, each $395 \mathrm{~mm}$ long and separated by $120^{\circ}$ angles, and were allowed to freely explore for $8 \mathrm{~min}$. Arm choices were manually recorded. Three consecutive choices of three different arms were counted as an alternation. The score was obtained by dividing the total number of alternations by the total number of choices minus 2 .

\subsection{Object recognition test}

Adult mice (PD60) were assessed for recognition memory as previously reported (Maccarrone et al., 2002) with minor modifications. The test was performed in a white Plexiglas box $(50 \mathrm{~cm}$ x $50 \mathrm{~cm}$ x $30 \mathrm{~cm}$ ) with white vertical walls under dim light intensity (30 lux) in the middle of the field. The objects to be discriminated were a black plastic figure (Object A) and a red wooden figure (Object B). Firstly, mice were individually habituated to the box for $15 \mathrm{~min}$. After $24 \mathrm{~h}$, the acquisition trial took place in which mice were allowed to explore the box for 10 min in the presence of either object A or object B alone (counterbalanced). A 10-min retention trial occurred $24 \mathrm{~h}$ later in which objects A and B were placed in the open-field. Time spent by 
the animal exploring object A (tA) and object $\mathrm{B}(\mathrm{tB})$ were recorded using Smart software (Panlab s.l.u., Spain). The recognition index (\%) was defined as $[\mathrm{tB} /(\mathrm{tA}+\mathrm{tB})] \times 100$ for the animals exploring object $A$ on the acquisition trial or $[\mathrm{tA} /(\mathrm{tA}+\mathrm{tB})] \times 100$ for the mice exploring object $\mathrm{B}$ during the acquisition trial.

\subsection{Sample preparation and western blot analysis}

Total protein extracts were isolated from PFC and HPC brain areas $(250 \mathrm{mg}$ tissue $/ 0.5 \mathrm{ml}$ lysis buffer) extracted from adult mice (PD70) after behavioural testing in the Y-maze apparatus and the object recognition test. Mice used in the rotarod experiments were not used for molecular assays. The tissue was first homogenized in cold lysis buffer (1\% Nonidet P-40, $20 \mathrm{mM}$ Tris$\mathrm{HCl} \mathrm{pH} 8,130 \mathrm{mM} \mathrm{NaCl}, 10 \mathrm{mM} \mathrm{NaF}, 10 \mu \mathrm{g} / \mathrm{ml}$ aprotinin, $10 \mu \mathrm{g} / \mathrm{ml}$ leupeptin, $10 \mathrm{mM}$ DTT, 1 $\mathrm{mM} \mathrm{Na} \mathrm{VO}_{4}$ and $1 \mathrm{mM}$ PMSF). Homogenates were kept on ice for $30 \mathrm{~min}$, centrifuged at $15,000 \mathrm{xg}$ for $15 \mathrm{~min}$., and the supernatant was collected to determine protein concentration. Also, to determine nuclear proteins, we isolated the cytoplasmic and nuclear extracts using the Epiquik Nuclear Extraction kit and carefully following the manufacturer's instructions (Epigentek, Farmingdale, NY). The lysate protein concentration was measured by the Pierce BCA (bicinchoninic acid) assay kit (Thermo Fisher Scientific, Spain). Lysates were then separated by SDS-PAGE gels and immunoblotting was performed as previously described (Alfonso-Loeches et al., 2010). Membranes were incubated overnight at $4^{\circ} \mathrm{C}$ with primary antibodies (see Table 1, below). After washing with TBS/T, blots were incubated with their respective HRP-conjugated antibodies: anti-rat (1/1000, Santa Cruz Biotechnology), anti-mouse (1/5000, Sigma Aldrich) or anti-rabbit (1/20000, Sigma Aldrich). Blots were developed using the ECL system (ECL Plus, Amersham Biosciences). Some membranes were stripped for $1 \mathrm{~h}$ at $60^{\circ} \mathrm{C}$ in SDS solution (2\% SDS, 0.85\% 2-ME, and $65 \mathrm{mM}$ Tris- $\mathrm{HCl}(\mathrm{pH} 6.8)$, washed, and incubated with anti-GAPDH (1/3000, Chemicon), anti-Lamin A/C (LMNA; 1/1000, Cell Signaling) or anti-Vinculin (1:10000, Abcam) for $2 \mathrm{~h}$ as loading controls. A densitometry analysis was assessed with Alpha-Ease FC, version Alpha Imager 2200 (Alpha Innotech Corporation). For comparative purposes, control values were normalized to $100 \%$ and the respective protein expression values were adjusted according to the normalization factor.

Table 1. Primary antibodies.

\begin{tabular}{|c|c|c|c|c|}
\hline Antibody & Description & Host & Dilution & Company \\
\hline Caspase-1 & Interleukin-1 converting enzyme (ICE) & Rabbit & $1: 100$ & $\begin{array}{c}\text { Santa Cruz } \\
\text { Biotechnology }\end{array}$ \\
\hline Caspase-3 & Caspase-3 p17 subunit (active) & Rabbit & $1: 1000$ & Cell Signaling \\
\hline GAPDH & $\begin{array}{c}\text { Glyceraldehyde 3-phosphate dehydrogenase (also } \\
\text { known as G3PDH) }\end{array}$ & Mouse & $1: 3000$ & Chemicon \\
\hline GFAP & Glial fibrillary acidic protein & Rabbit & $1: 500$ & Sigma Aldrich \\
\hline LMNA & Lamin $A / C$ & Mouse & $1: 1000$ & Cell Signaling \\
\hline MAG & Myelin-associated glycoprotein & Rabbit & $1: 5000$ & Abcam \\
\hline MBP & Myelin Basic Protein & Rat & 1:1000 & Abcam \\
\hline MYRF & Myelin Regulatory Factor & Rabbit & $1: 1000$ & Millipore \\
\hline
\end{tabular}




\begin{tabular}{|c|c|c|c|c|}
\hline NeuN & Neuronal Nuclei & Mouse & $1: 100$ & Chemicon \\
\hline NF-кB p65 & $\begin{array}{c}\text { Nuclear factor NF-Kappa-B p65 subunit (also known } \\
\text { as RelA) }\end{array}$ & Rabbit & $1: 50$ & $\begin{array}{c}\text { Santa Cruz } \\
\text { Biotechnology }\end{array}$ \\
\hline NLRP3 & $\begin{array}{l}\text { Nod-like receptor family, Pyrin Domain Containing } \\
\text { protein } 3 \text { (also known as CIAS1 or Cryopyrin) }\end{array}$ & Goat & $1: 1000$ & Abcam \\
\hline PLP & Myelin proteolipid protein (also known as lipophilin) & Rabbit & $1: 1000$ & Abcam \\
\hline TLR2 & Toll-like receptor 2 & Rabbit & $1: 200$ & $\begin{array}{c}\text { Santa Cruz } \\
\text { Biotechnology }\end{array}$ \\
\hline TLR4 & Toll-like receptor 4 & Mouse & $1: 200$ & $\begin{array}{c}\text { Santa Cruz } \\
\text { Biotechnology }\end{array}$ \\
\hline VCL & $\begin{array}{c}\text { Vinculin, membrane-cytoskeletal protein in focal } \\
\text { adhesion plaques }\end{array}$ & Rabbit & $1: 10000$ & Abcam \\
\hline
\end{tabular}

\subsection{Interleukin-1 $\beta$ enzyme-linked immunosorbent assay (ELISA)}

Brain tissue was homogenized in cold lysis buffer (1\% Nonidet P-40, $20 \mathrm{mM}$ Tris- $\mathrm{HCl} \mathrm{pH} 8$, $130 \mathrm{mM} \mathrm{NaCl}, 10 \mathrm{mM} \mathrm{NaF}, 10 \mu \mathrm{g} / \mathrm{ml}$ aprotinin, $10 \mu \mathrm{g} / \mathrm{ml}$ leupeptin, $10 \mathrm{mM} \mathrm{DTT}, 1 \mathrm{mM}$ $\mathrm{Na} 3 \mathrm{VO} 4$ and $1 \mathrm{mM}$ PMSF) (250 $\mathrm{mg}$ tissue $/ 0.5 \mathrm{ml}$ ). Lysis samples were kept on ice for $30 \mathrm{~min}$ and centrifuged at maximum speed $(13,000 \mathrm{rpm})$ for $15 \mathrm{~min}$. The supernatant was collected for protein and cytokine determination. Protein was determined by using the Pierce BCA (bicinchoninic acid) assay kit (Thermo Fisher Scientific, Spain). The cytokine levels of interleukin (IL)-1 $\beta$ were measured using the enzyme-linked immunosorbent assay kit (Bender MedSystems $\mathrm{GmbH}$, Austria), following the manufacturer's instructions, as previously reported (Alfonso-Loeches et al., 2016). The levels of IL-1 $\beta$ were expressed as $\mathrm{pg} / \mathrm{mg}$ of protein.

\subsection{Statistical analysis}

Results are expressed as the [mean \pm SEM]. Data obtained from the DID test were analyzed using two-way analysis of variance (ANOVA) with group as a between-subject factor and day as a within-subject factor, followed by Bonferroni post-hoc comparisons when required. Oneway ANOVA with repeated measures was used to analyze alcohol intake during the DID test. Behavioral and biochemical data were analyzed using unpaired two-tailed Student's t-test. Pearson's correlation analysis was used to explore correlations between the variables. In all experiments, differences were considered significant when the probability of error was less than 5\%. All statistical analyses were performed using GraphPad Prism 6 (GraphPad Software, San Diego, CA). 


\section{Results}

\subsection{Maternal binge-like alcohol consumption during prenatal and lactation periods}

DID procedure was performed to mimic voluntary binge alcohol consumption during gestation and lactation. Two-way ANOVA analysis of DID test of dams exposed to alcohol only during the three-week gestation period showed a significant effect of day $[\mathrm{F}(11,220)=27.44 ; \mathrm{p}<0.001]$, group $[\mathrm{F}(1,20)=70.33 ; \mathrm{p}<0.001]$ and interaction between both factors $[\mathrm{F}(11,220)=4.317$; $\mathrm{p}<0.001]$. Bonferroni post-hoc comparisons revealed that alcohol consumption was significantly higher on days $4(\mathrm{p}<0.001), 5(\mathrm{p}<0.05), 8(\mathrm{p}<0.001), 9(\mathrm{p}<0.01), 11(\mathrm{p}<0.05)$ and $12(\mathrm{p}<0.001)$ compared to volume consumed by water-drinking dams (Fig. 1A).

To analyze differences in alcohol intake between each drinking session, one-way ANOVA with repeated measures showed a significant effect of day $[F(11,99)=21.922 ; p<0.001]$. Furthermore, post-hoc comparisons revealed significant differences between day 4 compared with days 1 to 3 $(\mathrm{p}<0.001)$ and day 8 with days 5 to $7(\mathrm{p}<0.001)$, which correspond to the $4 \mathrm{~h}$ drinking sessions. However, on day 12 alcohol intake was not significantly different from days 9 to 11(Fig. 1C).

Two-way ANOVA analysis of the DID test in dams exposed to alcohol during the three-week gestation period and the three-week lactation period showed a significant effect of day $[F(23,345)=14.28 ; \mathrm{p}<0.001]$, group $[\mathrm{F}(1,15)=12.96 ; \mathrm{p}<0.01]$ and interaction between both factors $[\mathrm{F}(23,345)=6.650 ; \mathrm{p}<0.001]$. Post-hoc analysis showed that alcohol-drinking dams tended to show higher levels of volume consumed, but this was not statistically significant on day $4(p=0.0914)$. However, during the lactation period, consumption was significantly different between water and alcohol on days $17(\mathrm{p}<0.001), 18(\mathrm{p}<0.001), 19(\mathrm{p}<0.05), 21(\mathrm{p}<0.001), 22$ $(\mathrm{p}<0.05)$ and $23(\mathrm{p}<0.05)$, and was higher in water-drinking dams (Fig. 1B).

Similarly, one-way ANOVA with repeated measures for alcohol consumption levels showed a significant effect of day $[\mathrm{F}(23,391)=26.349 ; \mathrm{p}<0.001]$. Bonferroni post-hoc comparisons revealed significant differences between binge sessions and the 2-hour access sessions: day 4 compared to days 1 to 3 ( $p<0.001$ ), day 8 compared to days 5 to 7 ( $p<0.001$ ), day 12 compared to days 9 to $11(\mathrm{p}<0.001)$, day 16 compared to days 13 to $15(\mathrm{p}<0.05)$, day 20 compared to days 17 to $19(p<0.05)$ and day 24 compared to days 21 to 23 ( $p<0.001)$ (Fig. 1D).

Maternal body weight was measured at 2-day intervals during gestation and lactation periods. Two-way ANOVA analysis of body weight measures during prenatal DID test (Fig. 2A) showed a significant effect of day $[\mathrm{F}(5,140)=423.4 ; \mathrm{p}<0.001]$, but no significant effect of group $[F(1,28)=0.6283$; n.s. $]$ and no significant interaction between both factors $[F(5,140)=0.7445$; n.s.]. Two-way ANOVA analysis of body weight measures during prenatal and lactational DID test (Fig. 2B) showed a significant effect of day $[\mathrm{F}(11,132)=51.19 ; \mathrm{p}<0.001]$, but no significant effect of group $[F(1,12)=0.5037$; n.s. $]$ and no significant interaction between both factors $[\mathrm{F}(11,132)=0.5829 ;$ n.s. $]$.

One-way ANOVA analysis of food intake measurements during 24h ad libitum periods before and after birth (Table 2) showed an effect of group $[\mathrm{F}(3,10)=5.828 ; \mathrm{p}<0.05]$, but Bonferroni post-hoc comparisons revealed no significant differences between water- or alcohol-exposed females. A significant increase in food intake was found within water-exposed dams between pre- and postnatal periods $(\mathrm{p}<0.05)$. In regards with the measurement of water intake during $24 \mathrm{~h}$ ad libitum periods, one-way ANOVA analysis showed an effect of group $[\mathrm{F}(3,10)=14$; $\mathrm{p}<0.001]$. Furthermore, Bonferroni post-hoc comparisons revealed significant differences in the ad libitum water intake of water-exposed females during pregnancy compared with their consumption after parturition $(\mathrm{p}<0.01)$, as well as significant differences were found in the water intake of alcohol-exposed females between pre- and post-birth ad libitum consumption 
$(\mathrm{p}<0.01)$. Notwithstanding, no differences were found in the ad libitum water consumption between water- and alcohol-exposed females during pregnancy or breastfeeding.

Table 2. Food and water intake measurements during ad libitum periods.

\begin{tabular}{|c|c|c|c|c|}
\hline & \multicolumn{2}{|c|}{ Prenatal period } & \multicolumn{2}{c|}{ Postnatal period } \\
\hline & $\begin{array}{c}\text { Water- } \\
\text { exposed }\end{array}$ & $\begin{array}{c}\text { Alcohol- } \\
\text { exposed }\end{array}$ & $\begin{array}{c}\text { Water- } \\
\text { exposed }\end{array}$ & $\begin{array}{c}\text { Alcohol- } \\
\text { exposed }\end{array}$ \\
\hline $\begin{array}{c}\text { Food intake (gFood/kg body } \\
\text { weight/24h) }\end{array}$ & $142 \pm 5.87$ & $135.2 \pm 6.11$ & $223.7 \pm 12.3 *$ & $183.3 \pm 37.08$ \\
\hline $\begin{array}{c}\text { Water intake (gWater/kg body } \\
\text { weight/24h) }\end{array}$ & $116.8 \pm 28.43$ & $199.4 \pm 34.13$ & $525.5 \pm 93.52^{* *}$ & $658.5 \pm 84.38^{* *}$ \\
\hline
\end{tabular}

Table 2. Maternal food and water intake during ad libitum periods. Data are expressed as [mean $\pm \mathrm{SEM}$ ]. ${ }^{*} \mathrm{p}<0.05 ; *{ }^{*} \mathrm{p}<0.01$ comparisons between pre- and postnatal periods within the same group of dams $(\mathrm{n}=3$ 4 per group).

\subsection{Blood Alcohol Concentration measurement}

Blood Alcohol Concentrations (BAC) were measured after the final gestational binge-like session (day 12 of the test) with values [mean \pm SEM] of $79.27 \mathrm{mg} / \mathrm{dl} \pm 21.45$ and following the last binge drinking session during lactation (day 24 of the test) obtaining values of 81.57 $\mathrm{mg} / \mathrm{dl} \pm 12.89$ by GC-FID ( $\mathrm{n}=4-7$ per group). Furthermore, Pearson's correlation calculated between BAC values $(\mathrm{mg} / \mathrm{dl})$ and levels of volume of alcohol consumed $(\mathrm{ml})$ showed a significant positive correlation $(\mathrm{r}=0.5803 ; \mathrm{p}<0.05)$, as well as correlation between $\mathrm{BAC}$ values $(\mathrm{mg} / \mathrm{dl})$ and alcohol intake levels (g EtOH/kg body weight) $(\mathrm{r}=0.6877 ; \mathrm{p}<0.05)$ (Fig. 3 ).

\subsection{Maternal alcohol consumption induces long-term motor coordination deficits in the offspring}

To assess the effects of early alcohol exposure on motor coordination in late adolescent mice (PD48), the mean of the rpm achieved on the last four trials of the rotarod test was calculated. As shown in Figure 4, the mean of rpm was significantly lower in both prenatal alcohol-exposed (PAE) $\left(\mathrm{t}_{6}=2.848 ; \mathrm{p}<0.05\right)$ and prenatal and lactation alcohol-exposed (PLAE) $\left(\mathrm{t}_{14}=3.623\right.$; $\mathrm{p}<0.01)$ mice, suggesting motor coordination impairments in both groups.

\subsection{Prenatal and early postnatal alcohol exposure were required to induce working memory impairments later in adulthood}

To evaluate the long-term effects of early alcohol exposure on spatial working memory, the Ymaze spontaneous alternation test was performed in adult mice (PD60), a task mainly dependent on PFC function, but also involving other brain areas (Lalonde, 2002; Yoon et al., 2008). Student's t-test showed no significant differences on the percentage of spontaneous alternation between PAE mice and the control group ( $\mathrm{t}_{18}=0.6836$; n.s.) (Fig. 5A) whereas PLAE mice showed a significant decrease in the $Y$-maze score compared with their counterparts $\left(t_{16}=2.652\right.$; $\mathrm{p}<0.01$ ) (Fig. 5B). In addition, the score obtained in the Y-maze test tended to show a significant correlation with the corresponding maternal alcohol intake in PLAE mice as calculated by Pearson's coefficient of correlation ( $\mathrm{r}=-0.5657$; $\mathrm{p}=0.06$ ) (Fig. 5D). However, in PAE mice, the Pearson's correlation calculated between the score and the maternal alcohol 
intake $(\mathrm{g} \mathrm{EtOH} / \mathrm{kg})$ showed a negative correlation, albeit statistically insignificant $(\mathrm{r}=-0.3655$; n.s.) (Fig. 5C).

\subsection{Object recognition memory was not impaired by maternal binge-like alcohol consumption}

The object recognition test was used to assess the effects of maternal alcohol consumption on recognition memory, a hippocampal-dependent task, in adult mice (PD60) prenatally exposed to alcohol. Student's t-test showed no significant differences either between the recognition index (\%) of PAE mice and control group $\left(\mathrm{t}_{14}=0.6436\right.$; n.s.) or between PLAE and control mice $\left(\mathrm{t}_{11}=0.02086 ;\right.$ n.s. $)$ (data not shown).

\subsection{Maternal binge alcohol drinking induced persistent activation of neuroinflammatory pathways}

The expression of the innate immune receptors TLR4 and TLR2 was measured in the PFC and HPC of both PAE and PLAE adult mice (PD70). Student's t-test showed a significant increase in TLR4 expression in the PFC of PAE mice $\left(t_{5}=3.3949 ; p<0.05\right)$, whereas there were no significant differences in the HPC $\left(\mathrm{t}_{5}=0.2372\right.$; n.s.) (Fig. 6A). In PLAE mice, a significant increase of TLR4 expression was found in the PFC $\left(\mathrm{t}_{8}=2.84143 ; \mathrm{p}<0.05\right)$ as well as in the HPC $\left(\mathrm{t}_{6}=3.06974 ; \mathrm{p}<0.05\right)$ (Fig. 6B). As for the TLR2 expression, there were no significant differences either between PAE and control mice in the PFC $\left(t_{4}=1.46118\right.$; n.s. $)$ or in the HPC $\left(\mathrm{t}_{4}=1.17669\right.$; n.s.) (Fig. 6C). In PLAE mice, we found an increased TLR2 expression in the PFC $\left(\mathrm{t}_{8}=4.34934 ; \mathrm{p}<0.01\right)$ and the HPC $\left(\mathrm{t}_{8}=2.49116 ; \mathrm{p}<0.05\right)$ (Fig. 6D). The NFKB/p65 levels increased in the nuclear extracts of the PFC $\left(\mathrm{t}_{6}=3.91569 ; \mathrm{p}<0.01\right)$ and the HPC $\left(\mathrm{t}_{6}=2.50579\right.$; $\mathrm{p}<0.05$ ) of PAE animals (Fig. 6E). In PLAE mice, NFKB/p65 levels increased in the PFC $\left(\mathrm{t}_{8}=2.42713 ; \mathrm{p}<0.05\right)$ and a tendency towards a statistically significant increased expression was found in the HPC $\left(\mathrm{t}_{8}=2.12697 ; \mathrm{p}=0.06\right)$ (Fig. 6F).

As shown in Figure 7, NLRP3, an inflammasome protein, and caspase-1 levels were also analyzed in the PFC and HPC of PAE and PLAE mice. An increase in NLRP3 expression was found in the PFC of PAE mice $\left(\mathrm{t}_{6}=3.222 ; \mathrm{p}<0.05\right)$ but no differences were found in the HPC $\left(\mathrm{t}_{4}=1.8692 ;\right.$ n.s. $)$. Similar results were obtained in PLAE mice, NLRP3 expression increased in the PFC $\left(\mathrm{t}_{8}=5.2111 ; \mathrm{p}<0.001\right)$ whereas it remained unchanged in the HPC $\left(\mathrm{t}_{6}=0.8661 ;\right.$ n.s. $)$. Caspase- 1 expression was significantly increased in the PFC $\left(t_{5}=3.2188 ; p<0.05\right)$ but it was not significantly altered in the HPC $\left(\mathrm{t}_{6}=1.1187\right.$; n.s.) of PAE mice. In PLAE mice a significant increase of caspase- 1 expression was found in the PFC $\left(\mathrm{t}_{7}=2.7096 ; \mathrm{p}<0.05\right)$ and also in the HPC $\left(t_{4}=5.9977 ; p<0.01\right)$. In addition, the IL-1 $\beta$ cytokine levels were measured using ELISA. Student's t-test revealed a significant increase in the PFC of PAE mice $\left(t_{8}=2.63128 ; p<0.05\right)$. However, in the HPC there were no significant differences in the IL- $1 \beta$ expression $\left(t_{5}=0.9188\right.$; n.s.) (Fig. 7E). In contrast, in the PFC of PLAE mice, Student's t-test showed no significant differences in the expression of IL-1 $\beta\left(\mathrm{t}_{4}=2.05368\right.$; n.s. $)$, whereas in the HPC it was found significantly increased $\left(\mathrm{t}_{4}=3.0009 ; \mathrm{p}<0.05\right)$ (Fig. 7F).

In addition, Pearson's correlation analyses were performed between data obtained from offspring's biochemical studies and each corresponding maternal alcohol intake (mean of binge sessions) (Table 3).

Table 3. Pearson's correlation analyses 


\begin{tabular}{|c|c|c|c|}
\hline & & PAE group & PLAE group \\
\hline \multirow[t]{6}{*}{ Prefrontal cortex } & TLR4 & $\mathrm{r}=0.7952 ; \mathrm{p}<0.05$ & $\mathrm{r}=0.7042 ; \mathrm{p}<0.05$ \\
\hline & TLR2 & $\mathrm{r}=0.5753 ;$ n.s. & $\mathrm{r}=0.8169 ; \mathrm{p}<0.01$ \\
\hline & NFкB/p65 & $\mathrm{r}=0.9217 ; \mathrm{p}<0.01$ & $\mathrm{r}=0.6162 ;$ n.s. \\
\hline & NLRP3 & $\mathrm{r}=0.7401 ; \mathrm{p}<0.05$ & $\mathrm{r}=0.7587 ; \mathrm{p}<0.05$ \\
\hline & Caspase1 & $\mathrm{r}=0.8677 ; \mathrm{p}<0.05$ & $\mathrm{r}=0.687 ; \mathrm{p}<0.05$ \\
\hline & IL-1及 & $\mathrm{r}=0.7148 ; \mathrm{p}<0.05$ & $\mathrm{r}=0.4827$; n.s. \\
\hline \multirow[t]{6}{*}{ Hippocampus } & TLR4 & $\mathrm{r}=0.1195 ;$ n.s. & $\mathrm{r}=0.8826 ; \mathrm{p}<0.01$ \\
\hline & TLR2 & $\mathrm{r}=-0.3959 ;$ n.s. & $\mathrm{r}=0.7753 ; \mathrm{p}<0.01$ \\
\hline & NFкB/p65 & $\mathrm{r}=0.4121 ;$ n.s. & $\mathrm{r}=0.8095 ; \mathrm{p}<0.01$ \\
\hline & NLRP3 & $\mathrm{r}=0.6705 ;$ n.s. & $\mathrm{r}=0.5629 ;$ n.s. \\
\hline & Caspase1 & $\mathrm{r}=0.5083 ;$ n.s. & $\mathrm{r}=0.9293 ; \mathrm{p}<0.01$ \\
\hline & IL-1及 & $\mathrm{r}=0.2919 ;$ n.s. & $\mathrm{r}=0.8267 ; \mathrm{p}<0.05$ \\
\hline
\end{tabular}

\subsection{Early alcohol exposure induced glial activation and neuron cell damage}

The expression of the glial fibrillary acidic protein (GFAP) was assessed in the PFC and HPC of PAE and PLAE mice. Student's t-test revealed an increase of GFAP expression in the PFC $\left(t_{4}=3.0009 ; p<0.05\right)$, whereas there were no differences in the HPC $\left(t_{7}=0.2945 ; n\right.$.s. $)$ of PAE mice (Fig. 8A). In PLAE mice, a significant increase of GFAP expression was found in both the PFC $\left(t_{5}=2.5758 ; p<0.05\right)$ and HPC $\left(t_{5}=3.5692 ; p<0.05\right)$ (Fig. 8B). Furthermore, Neuronal Nuclei $(\mathrm{NeuN})$ marker expression was analyzed in the PFC and HPC. No significant differences were found in the PFC of PAE mice $\left(t_{5}=1.3712\right.$; n.s.), although a tendency towards a significant reduction of NeuN expression was revealed in the HPC of mice prenatally exposed to binge alcohol ( $\mathrm{t}_{4}=2.7154 ; \mathrm{p}=0.05$ ) (Fig. 8C). In PLAE mice (Fig. 8D), a significant reduction of NeuN expression was found in the PFC $\left(t_{4}=4.0306 ; \mathrm{p}<0.05\right)$. However, no differences were found in the HPC of PLAE mice $\left(\mathrm{t}_{5}=1.3602 ;\right.$ n.s.). In addition, caspase-3/p17 expression was assessed to investigate whether cell loss was due to alcohol-induced apoptosis. In PAE mice (Fig. 8E), Student's t-test showed no significant differences in the PFC $\left(\mathrm{t}_{5}=1.5552 ; \mathrm{n} . \mathrm{s}\right.$.) or HPC $\left(\mathrm{t}_{5}=1.233\right.$; n.s.). However, a significant increase of caspase-3/p17 was found in the PFC of PLAE mice $\left(t_{5}=5.689 ; p<0.01\right)$, whereas no differences were found in the HPC $\left(t_{4}=0.1898 ;\right.$ n.s. $)$ (Fig. 8F). Additionally, Pearson's correlation analyses were performed between these markers of gliosis and brain damage and each corresponding maternal alcohol intake (mean of binge sessions) (Table 4).

Table 4. Pearson's correlation analyses

\begin{tabular}{|c|c|c|c|}
\hline & & PAE group & PLAE group \\
\hline Prefrontal cortex & GFAP & $\mathrm{r}=0.7471 ;$ n.s. & $\mathrm{r}=0.7492 ;$ n.s. \\
\hline
\end{tabular}




\begin{tabular}{|l|c|c|c|}
\hline \multirow{2}{*}{} & NeuN & $\mathrm{r}=0.4608 ; \mathrm{n} . \mathrm{s}$. & $\mathrm{r}=-0.8766 ; \mathrm{p}<0.05$ \\
\cline { 2 - 4 } & Caspase-3 & $\mathrm{r}=0.5642 ; \mathrm{n} . \mathrm{s}$. & $\mathrm{r}=0.9663 ; \mathrm{p}<0.001$ \\
\hline \multirow{2}{*}{ Hippocampus } & GFAP & $\mathrm{r}=0.0448 ; \mathrm{n} . \mathrm{s}$. & $\mathrm{r}=0.8459 ; \mathrm{p}<0.05$ \\
\cline { 2 - 4 } & NeuN & $\mathrm{r}=0.7984 ;$ n.s. & $\mathrm{r}=-0.5786 ;$ n.s. \\
\cline { 2 - 4 } & Caspase-3 & $\mathrm{r}=0.4222 ;$ n.s. & $\mathrm{r}=-0.0027 ;$ n.s. \\
\hline
\end{tabular}

\subsection{Persistent effects of early alcohol exposure on myelin proteins}

The expression of myelin-associated glycoprotein (MAG), myelin basic protein (MBP) and myelin proteolipid protein (PLP) was assessed for each experimental condition to study the persistent effects of maternal binge alcohol consumption on myelin integrity. Student's t-test showed a decreased expression of MAG $\left(\mathrm{t}_{10}=2.6544 ; \mathrm{p}<0.05\right)$ and PLP $\left(\mathrm{t}_{8}=3.06885 ; \mathrm{p}<0.05\right)$ proteins, but no statistically significant differences were found in the expression of MBP $\left(t_{6}=2.2660 ; p=0.06\right)$ in the PFC of PAE mice (Fig. 9A). MAG levels were also found to have significantly decreased $\left(\mathrm{t}_{6}=2.84173 ; \mathrm{p}<0.05\right)$ as well as PLP levels $\left(\mathrm{t}_{7}=3.1494 ; \mathrm{p}<0.05\right)$, but no differences were appreciated in MBP $\left(\mathrm{t}_{6}=1.33305\right.$; n.s.) expression in the HPC of PAE mice (Fig. 9C). In addition, a diminished expression of $\mathrm{MAG}\left(\mathrm{t}_{8}=3.11658 ; \mathrm{p}<0.05\right)$, MBP $\left(\mathrm{t}_{8}=3.60847 ; \mathrm{p}<0.01\right)$ and PLP $\left(\mathrm{t}_{8}=2.47675 ; \mathrm{p}<0.05\right)$ proteins was revealed in the PFC of PLAE mice compared with the control group (Fig. 9B). Similarly, in the HPC of PLAE animals a decrease was found in the expression of MAG $\left(\mathrm{t}_{6}=5.179 ; \mathrm{p}<0.01\right)$, MBP $\left(\mathrm{t}_{8}=2.62483 ; \mathrm{p}<0.05\right)$ and PLP $\left(\mathrm{t}_{8}=3.03391 ; \mathrm{p}<0.05\right)$ proteins (Fig. 9D). Furthermore, the expression levels of the major myelin regulatory factor MYRF were analyzed in the PFC and HPC of PAE and PLAE mice (Fig. 10). Student's t-test showed a significant reduction of MYRF expression in the PFC $\left(\mathrm{t}_{6}=3.07389 ; \mathrm{p}<0.05\right)$ but no differences were found in the HPC $\left(\mathrm{t}_{8}=0.37167\right.$; n.s. $)$ of PAE mice compared with their counterparts. In PLAE mice, MYRF expression was found significantly diminished in both the PFC $\left(\mathrm{t}_{6}=3.91857 ; \mathrm{p}<0.01\right)$ and HPC $\left(\mathrm{t}_{7}=2.9443 ; \mathrm{p}<0.05\right)$ brain areas.

In addition, Pearson's correlation analyses were performed between offspring's myelin-related protein expression and each corresponding mean of maternal alcohol intakes during binge sessions (Table 5).

Table 5. Pearson's correlation analyses

\begin{tabular}{|c|c|c|c|}
\hline & & PAE group & PLAE group \\
\hline \multirow{3}{*}{ Prefrontal cortex } & MAG & $\mathrm{r}=-0.6123 ; \mathrm{p}<0.05$ & $\mathrm{r}=-0.7339 ; \mathrm{p}<0.05$ \\
\cline { 2 - 4 } & MBP & $\mathrm{r}=-0.4661 ;$ n.s. & $\mathrm{r}=-0.6624 ; \mathrm{p}<0.05$ \\
\cline { 2 - 4 } & PLP & $\mathrm{r}=-0.7293 ; \mathrm{p}<0.05$ & $\mathrm{r}=-0.6191 ;$ n.s. \\
\cline { 2 - 4 } & MYRF & $\mathrm{r}=-0.7893 ; \mathrm{p}<0.05$ & $\mathrm{r}=-0.83 ; \mathrm{p}<0.05$ \\
\hline \multirow{3}{*}{ Hippocampus } & MAG & $\mathrm{r}=-0.8101 ; \mathrm{p}<0.05$ & $\mathrm{r}=-0.9381 ; \mathrm{p}<0.001$ \\
\cline { 2 - 4 } & MBP & $\mathrm{r}=-0.3722 ;$ n.s. & $\mathrm{r}=-0.6879 ; \mathrm{p}<0.05$ \\
\cline { 2 - 4 } & PLP & $\mathrm{r}=-0.7798 ; \mathrm{p}<0.05$ & $\mathrm{r}=-0.6646 ; \mathrm{p}<0.05$ \\
\hline
\end{tabular}




\begin{tabular}{|l|l|l|c|}
\hline & MYRF & $\mathrm{r}=-0.206 ; \mathrm{n} . \mathrm{s}$. & $\mathrm{r}=-0.756 ; \mathrm{p}<0.05$ \\
\hline
\end{tabular}

Furthermore, to study whether an association between neuroimmune activation and myelin damage exists, Pearson's correlation analyses were performed between the levels of all proinflammatory molecules analyzed and myelin proteins in the PFC and HPC of both PAE and PLAE mice. We found a statistically significant negative correlation between Caspase-1 levels and MYRF expression in the PFC of PAE mice $(r=-1 ; \mathrm{p}<0.01)$, whereas in the HPC we found a positive correlation between IL-1 $\beta$ and PLP expression levels $(\mathrm{r}=1 ; \mathrm{p}<0.001)$. In PLAE mice, we found a negative correlation between NLRP3 inflammasome and MBP expression levels $(r=-0.964 ; p<0.05)$ and also between Caspase 1 and PLP expression levels $(r=-0.950 ; p=0.05)$ in the PFC. In the HPC of PLAE mice, a significant negative correlation was found between $\mathrm{NF \kappa B} / \mathrm{p} 65$ transcription factor expression and PLP levels $(\mathrm{r}=-0.985 ; \mathrm{p}<0.05)$. Correlations among the other proteins analyzed were not statistically significant. 


\section{Discussion}

\section{Animal model and behavioral effects induced by prenatal and postnatal alcohol exposure}

Using an animal model of maternal binge-like alcohol consumption, the present study shows that prenatal alcohol exposure and/or in combination with early postnatal exposure induces an increase of pro-inflammatory molecules expression and diminished expression of myelin proteins in the HPC and PFC of alcohol-exposed offspring. Furthermore, these alterations were associated with persistent motor function and cognitive deficits in young adult mice.

Alcohol consumption during gestation, even in moderate doses, may have deleterious effects on the early development of the fetus and continued growth and development after birth (Jacobson and Jacobson, 2002; Jacobson, 1997; Valenzuela et al., 2012). The CNS is especially vulnerable to the teratogenic actions of alcohol due to its extended developmental period, and its related alterations are among the most severe manifestations of FASD, impairing a wide range of processes such as learning, memory, attention, fine motor coordination, judgment, social interaction and emotional behavior (Riley et al., 2011). However, the subsequent behavioral outcome is markedly influenced by factors including the level and pattern of alcohol exposure, the route of administration and the timing of alcohol exposure during development. We exposed dams to a voluntary mouse model of binge-like alcohol drinking known as the DID test (Rhodes et al., 2005; Thiele et al., 2014), devised to prevent mothers from undergoing stressful situations. This limited access model, in which pregnant females voluntarily drink alcohol and reach high BACs that may lead to behavioral impairments, appropriately recreates the bingeing patterns observed in some human alcoholics (Boehm et al., 2008; Crabbe et al., 2011; Sprow and Thiele, 2012). In our study, dams showed a higher alcohol intake during the binge drinking sessions ( $4 \mathrm{~h}$ access) compared with the three previous days ( $2 \mathrm{~h}$ access) of each week. Females exposed to the DID test during gestation underwent three binge episodes, whereas dams exposed during gestation and lactation underwent a total of six binge episodes (three during gestation and three during lactation) reaching BAC levels of intoxication as defined by the NIAAA (2016), approximately $80 \mathrm{mg} / \mathrm{dl}$. Although alcohol intake diminished throughout the prenatal period, the reduction could be attributed to the increase in maternal body weight throughout pregnancy as opposed to changes in the volume consumed. In addition, we found a positive correlation between alcohol intake levels, volume consumed and blood levels, suggesting that the dams that drank more induced more defects in their progeny, since alcohol readily crosses the placenta and can be detected in the fetus within 1 min following a rise in maternal BAC (Burd et al., 2012). Additionally, the increase observed in water consumption during lactational DID procedure was also observed in both water- and alcohol-exposed females during ad libitum access periods after parturition. Therefore, it may be attributed to an increased physiological demand for fluid intake to support milk production (Bentley, 1998). Notwithstanding, food intake and maternal body weight were not affected by alcohol consumption since no differences were found between groups.

Scarce studies have used the DID procedure as a model of prenatal and postnatal binge-like alcohol exposure. In a previous study (Boehm et al., 2008), DID test paradigm was employed throughout the gestational period to model FASD in C57BL/6 mice. Our study differs from this in that we extended maternal alcohol consumption until weaning (PD-21), given that a significant phase of brain development occurs after birth in rodents (Patten et al., 2014). Furthermore, it better mimics the human condition in which some alcoholic mothers continue to drink throughout the breastfeeding period (Breslow et al., 2007). When a lactating woman 
consumes alcohol, it is transferred into the milk paralleling the levels found in the maternal blood (Guerri and Sanchis, 1986). Alcohol administered through the breast milk may alter offspring behavior and early development, but scarce research data is available about the longterm effects of binge-like alcohol drinking during lactation (Mennella, 2001; Haastrup et al., 2014).

Offspring from dams exposed to the DID test during gestation and lactation periods did not differ in weight, litter size or pup mortality from their counterparts, yet behavioral assessment at late adolescence and adulthood yielded to lifelong cognitive deficits and motor coordination impairments. In humans with FAS, microcephaly, agenesis of the corpus callosum, errors in migration and anomalies in the CNS development have been reported in postmortem studies. Neuroimaging studies also revealed overall brain volume reductions in FASD patients (Guerri et al., 2009). In agreement with human findings, rodent models of PAE have shown reductions in brain and body weight and reduced litter size in alcohol-exposed offspring (Abbott et al., 2016; An and Zhang, 2015; Chappell et al., 2007; Comeau et al., 2014; Dasgupta et al., 2007; El Shawa et al., 2013; Helfer et al., 2014). Nevertheless, other studies reported no differences in litter size or pup weight in rodent models of alcohol exposure in utero, which is consistent with our results (Allan et al., 2003; Barbier et al., 2009; Brady et al., 2012; Choi et al., 2005; Cullen et al., 2014; Hausknecht et al., 2014; Kleiber et al., 2011; Savage et al., 2002). Interestingly, Boehm et al. (2008) reported reduced body weight in adolescent offspring mice, but not in adult mice, suggesting that this deficit had been reversed by compensatory mechanisms. Differences in the alcohol dose administered and timing of exposure may account for such discrepancies in the literature.

FASD patients show deficits in fine motor control tasks and postural balance (Connor et al., 2006; Lucas et al., 2014). In our study, motor coordination impairments were found in PAE and PLAE mice in late adolescence evaluated by the accelerating rotarod test, involving a whole network of motor skill learning-associated brain areas (Scholz et al., 2015; Shiotsuki et al., 2010). Our findings are consistent with other studies of fetal alcohol exposure, although a few discrepancies regarding this issue do exist in the literature. Motor deficits were found following continuous prenatal access to $24 \% \mathrm{v} / \mathrm{v}$ alcohol in rats (Tong et al., 2013) and also in mice prenatally exposed to $18 \% \mathrm{v} / \mathrm{v}$ alcohol (Cebolla et al., 2009). However, the prenatal DID test did not alter rotarod performance either in adolescent or adult mice offspring (Boehm et al., 2008) and after chronic intragastric administration of $6 \mathrm{~g} \mathrm{EtOH} / \mathrm{kg} /$ day throughout gestation, no rotarod impairments were found in adult rat offspring (Dursun et al., 2006), although higher maternal BACs were reached in those studies $(124-180 \mathrm{mg} / \mathrm{dl}$ and $334.45 \pm 18 \mathrm{mg} / \mathrm{dl}$, respectively).

A subtle range of cognitive defects has also been described in children prenatally exposed to alcohol, including disabilities in learning and memory, social interaction, attention and hyperactivity (Clarke and Gibbard, 2003). Although no alterations were found in PAE mice, we showed a deficit in working memory as assessed by the Y-maze test in adult PLAE mice. Nevertheless, no impairment was found in the object recognition test, which recruits not only the HPC but also its interactions with the perirhinal cortex and the medial PFC (Barker and Warburton, 2011). Accordingly, deficits on spatial learning and memory have been reported in different preclinical models of fetal alcohol exposure (Berman and Hannigan, 2000; Marquardt and Brigman, 2016). Rats prenatally exposed to alcohol showed spatial working and reference memory impairments that became more evident as task difficulty increased (Popović et al., 2006). Also, executive function impairments assessed by reversal learning in the Y-maze were 
found in PAE adolescent and adult mice (Allan et al., 2014; Marquardt et al., 2014), thus supporting our results. However, previous studies administering chronic moderate doses of alcohol $(6 \% \mathrm{v} / \mathrm{v}$ alcohol $)$ did not show impairments in the Y-maze task in either adult or aged rats (Cullen et al., 2014). Such discrepancies with our results may be due to the lower concentration of alcohol used $(6 \% \mathrm{v} / \mathrm{v})$, the lower maternal BACs achieved $(\sim 30 \mathrm{mg} / \mathrm{dl})$, the different ages at which offspring were tested and differences in species. Indeed, the levels of alcohol consumption by mothers appear to be related to the behavioral outcome observed in the offspring. Accordingly, the spontaneous alternation score showed an almost significant negative correlation with the maternal BAC in PLAE mice, whereas this was not found in PAE mice, showing no impairment in the Y-maze task. Additionally, studies of voluntary prenatal alcohol drinking showed that adult offspring of dams with continuous access to a $10 \% \mathrm{v} / \mathrm{v}$ alcohol solution had increased novelty exploratory behavior (Allan et al., 2003) or delayed learning acquisition in the Barnes maze test, a spatial reference memory task (Kleiber et al., 2011). In C57BL/6J mice (Brady et al., 2012), a limited access to a solution of 10\% v/v alcohol during gestation produced deficits in the delay-non-match-to-place spatial memory test, a hippocampaldependent learning task in adult offspring. In fact, PAE induces long-term deficits in synaptic plasticity in the HPC as a result of numerous subtle neuronal changes (Fontaine et al., 2016), which may underlie some of the behavioral abnormalities described. Although we did not find differences in the object recognition test in alcohol-exposed mice compared with their counterparts, we cannot discard the fact that binge alcohol exposure did not produce any impairment in the HPC. Greater behavioral alterations were found in the group of mice that received both pre- and postnatal alcohol exposure possibly due to a cumulative effect of alcohol exposure or because of the developmental timing of alcohol exposure during early postnatal development. Indeed, some brain areas are perinatal developed, such as the HPC, in both rodents and humans (Semple et al., 2013a).

\section{Effects of alcohol exposure during fetal and postnatal development on neuroinflammation associated with myelin damage}

Neuroimmune response alterations and inflammatory reactions are effects produced by early alcohol exposure in the brain that could be possible molecular mechanisms underlying the behavioral and cognitive alterations observed. Therefore, molecular markers of the neuroimmune response, neuronal and myelin proteins were examined in the PFC and HPC. We observed enhanced expression of pro-inflammatory factors in the brain of PAE and PLAE adult mice compared with their counterparts, suggesting that early binge-like alcohol exposure induces persistent neuroimmune alterations that remain until adulthood. TLR4, NF-кB/p65, NLRP3, caspase-1 and IL-1 $\beta$ levels increased mainly in the PFC after gestational alcohol exposure. In contrast, pre- and postnatal alcohol exposure led to an increase of all aforementioned markers, as well as TLR2, in the PFC and HPC. Indeed, most of the neuroimmune markers analyzed correlated positively with each corresponding maternal alcohol intake, suggesting that the more alcohol consumed, would lead to greater activation of the proinflammatory pathways. Recent studies have also demonstrated that alcohol intake activates the innate immune system in the CNS, leading to neuroinflammation and contributing to brain damage and behavioral dysfunctions. Such studies have shown that alcohol or alarmins (e.g. HMGB1), both in vitro and in vivo, are capable of activating innate immune receptors, such as TLRs, in glial cells triggering TLR4-dependent downstream pro-inflammatory transcription factors, such as AP-1 and NF-KB, resulting in the production of cytokines, chemokines and inflammatory mediators (Alfonso-Loeches et al., 2010; Crews and Vetreno, 2014; Fernandez- 
Lizarbe et al., 2013, 2009; Montesinos et al., 2015). Alcohol also induces the recruitment of NLRP3 inflammasome multiprotein complex via TLR4 in glial cells stimulating the cleavage of pro-IL1 $\beta$ by the activated cysteine-protease caspase- 1 along with reactive oxygen species (ROS) formation to generate IL-1 $\beta$ amplifying the neuroinflammatory response (Lippai et al., 2013; Montesinos et al., 2016). In fact, in TLR $4^{-/-}$mice the inflammatory response and brain damage induced by alcohol was completely abrogated (Alfonso-Loeches et al., 2010; Fernandez-Lizarbe et al., 2009), supporting the role of TLR4 signaling in alcohol-induced neuroinflammation. However, although the effects of alcohol on immune response in adolescents and adults have been widely documented (Alfonso-Loeches et al., 2010; Crews and Vetreno, 2014; Montesinos et al., 2016, 2015), the significance of neuroimmune activation during the early stages of the developing brain and the pathological and behavioral consequences are still uncertain.

The stimulation of glial cells and the up-regulation of pro-inflammatory factors in several brain regions have been reported in neonatal rats exposed to high alcohol levels (Boschen et al., 2016; Drew and Kane, 2014; Terasaki and Schwarz, 2016; Topper et al., 2015), suggesting that alcohol exposure during the rodent neonatal period, equivalent to the third trimester of human gestation (Alfonso-Loeches and Guerri, 2011), induces glial activation and cytokine production, leading to neuroinflammatory processes. Accordingly, we reported an increase of GFAP expression in mice developmentally exposed to alcohol bingeing, suggesting an activation of astrocytes. Indeed, alcohol-induced neuroinflammation is a key factor in neurotoxicity observed in FASD (Chastain and Sarkar, 2014; Saito et al., 2016) as alterations in glial cell function may affect neuronal development and survival, contributing to neurodegeneration and subsequently impairing brain connectivity and function (Glass et al., 2010; Guizzetti et al., 2014; Heneka et al., 2014; Wilhelm and Guizzetti, 2015). Sustained activation of microglia and astrocytes causes the production of pro-inflammatory and neurotoxic factors, such as IL-1 $\beta$, chemokines and ROS, which may result in neurodegeneration by activating apoptotic cell death of vulnerable neurons (Lehnardt, 2010; Simi et al., 2007). Accordingly, a diminished expression of NeuN has been found in mice receiving alcohol during both gestation and lactation, suggesting a neuronal cell loss probably induced by maternal binge alcohol drinking and its subsequent proinflammatory glial reactions. In addition, the reduction in NeuN levels could also be attributed to the potential effect of alcohol on inhibiting neurogenesis during development (Gil-Mohapel et al., 2010), which may result in reduced basal levels of neurons. However, we reported an increase of caspase- 3 activity in the PFC, the same brain area where a diminished expression of NeuN has been observed in PLAE mice, which evidences an apoptotic cell death induced by developmental alcohol exposure. Similarly, previous studies reported that alcohol exposure during the period of synaptogenesis, also known as the brain growth spurt period, triggers widespread apoptotic neurodegeneration in the rodent brain (Ikonomidou et al., 2000; Olney et al., 2002a, 2002b). Therefore, our results would suggest that maternal binge-like alcohol exposure induces a persistent dysregulation of the neuroimmune response in the offspring with a potentially significant impact on long-term alcohol-related impairments in learning, memory and behavioral dysfunction, such as those we have reported in executive functioning. Accordingly, recent evidence indicates that, although the immune system plays a key role during development, dysregulation or activation of immune functions during early brain development may cause long-term effects on both neuronal function and cognitive impairment. For instance, IL-1 $\beta$ within the HPC seems to be required for the maintenance of long-term potentiation, but elevated levels of IL-1 $\beta$ may impair learning and memory processes (Bilbo et al., 2012). 
Abnormalities in myelination and white matter structure are widespread alterations in FASD patients, suggesting that myelin and oligodendrocyte development are targets of developmental alcohol exposure (Sowell et al., 2008). For instance, it has been found a reduction of white matter associated with poorer myelination in children with FASD producing a deficit in information processing that may mediate the behavioral deficits observed (Fan et al., 2016). Myelin disruptions have also been observed in preclinical models of FASD and such effects may lead to deficient neuronal transmission, contributing to neurocircuitry impairments and cognitive dysfunctions (Guizzetti et al., 2014). Accordingly, we show that the persistent neuroimmune alterations induced by early alcohol exposure were associated with changes in protein components of the myelin sheath in both the PFC and HPC. MAG and PLP proteins were significantly reduced in the PFC and the HPC of PAE mice, while the MBP protein levels were not altered by in utero alcohol exposure alone. However, exposure to alcohol during preand postnatal development, when myelination and synaptogenesis take place in the rodents (Semple et al., 2013b) induced a significant reduction in the levels of MAG, MBP and PLP in both the PFC and HPC of PLAE mice. Furthermore, we reported a decrease in MYRF expression induced by early alcohol exposure, which is required for myelination by oligodendrocytes (Emery et al., 2009; Mitew et al., 2014). Additionally, myelin protein expression correlated negatively with maternal alcohol consumption, indicating that higher amounts of alcohol intake induce greater myelin protein disruptions. Therefore, our results reveal that combined pre- and postnatal binge alcohol exposure leads to persistent myelination deficiencies. Indeed, alterations in oligodendrocyte survival and maturation may disrupt the formation of myelin sheaths affecting efficient neuronal transmission and cognitive development. Alcohol-induced myelin disruptions might also impair the neurotransmission in corticocerebellar projections affecting motor skill learning (McKenzie et al., 2014) as observed in PAE and PLAE mice in late adolescence. In fact, poor rotarod performance has been previously associated with hypomyelination (Kuhn et al., 1995). In addition, MIA also induced myelin and axonal abnormalities in the PFC and HPC of the offspring (Farrelly et al., 2015; Makinodan et al., 2008), suggesting an involvement of pro-inflammatory signaling in myelination defects. In fact, negative correlations have been found between the expression of inflammatory markers and myelin proteins analyzed, indicating that an increase in the expression of pro-inflammatory mediators is associated with a reduction in the expression of constitutive myelin proteins. The association between alcohol-induced TLR4 activation and neuroinflammation with myelin derangements was also observed in the brain of adolescent and adult mice after binge alcohol drinking (Alfonso-Loeches et al., 2012; Montesinos et al., 2015), suggesting the role of the immune system and TLR4 signaling in the myelin changes observed in mice exposed to alcohol during brain development.

\section{Conclusions}

The current study reported that voluntary binge-like alcohol drinking during gestation and/or lactation periods induces persistent up-regulation of TLR-dependent pro-inflammatory pathways in glial cells leading to neurodegeneration and myelin damage along with persistent behavioral dysfunctions in the offspring, such as spatial working memory deficits and motor coordination impairments. Molecular alterations have been described in the PFC and HPC of prenatal alcohol-exposed offspring, being more evident after pre- and postnatal alcohol exposure. Whether the persistent neurobehavioral dysfunctions are related to neuroinflammation and/or myelin disruptions is presently unknown, but the present findings suggest that anti- 
inflammatory compounds should be considered in the prevention of alcohol-induced brain damage during development, and ameliorating the cognitive impairments. 


\section{Acknowledgements}

The authors wish to thank Mrs. Laia Castell for her support in experimental procedures, and Mrs. Anna Garrido and Mrs. Neus Mondragón for their technical assistance. This study was supported by grants from the European Union's Horizon 2020 research and innovation program 2014-2020 under Grant Agreement No 634143, Spanish Ministry of Economy, Innovation and Competitiveness (SAF2013-41761-R-FEDER; SAF2015-69187-R-FEDER; SAF2016-75347-R; SAF2016-75966-R), Spanish Ministry of Health (Retic-ISCIII-RD/12/0028/007 and RD/12/0028/0024-FEDER), Plan Nacional sobre Drogas (\#2014/020, \#2014/010 and \#2016/004) and Generalitat de Catalunya (2014SGR34). R. López-Arnau position was funded by an institutional program of the Universitat de Barcelona in collaboration with Obra Social of Fundació Bancària La Caixa. The authors declare no conflicts of interest. 


\section{References}

Abbott, C.W., Kozanian, O.O., Kanaan, J., Wendel, K.M., Huffman, K.J., 2016. The Impact of Prenatal Ethanol Exposure on Neuroanatomical and Behavioral Development in Mice. Alcohol. Clin. Exp. Res. 40, 122-133. doi:10.1111/acer.12936

Alfonso-Loeches, S., Guerri, C., 2011. Molecular and behavioral aspects of the actions of alcohol on the adult and developing brain. Crit. Rev. Clin. Lab. Sci. 48, 19-47. doi: $10.3109 / 10408363.2011 .580567$

Alfonso-Loeches, S., Pascual-Lucas, M., Blanco, A.M., Sanchez-Vera, I., Guerri, C., 2010. Pivotal role of TLR4 receptors in alcohol-induced neuroinflammation and brain damage. J. Neurosci. 30, 8285-95. doi:10.1523/JNEUROSCI.0976-10.2010

Alfonso-Loeches, S., Pascual, M., Gómez-Pinedo, U., Pascual-Lucas, M., Renau-Piqueras, J., Guerri, C., 2012. Toll-like receptor 4 participates in the myelin disruptions associated with chronic alcohol abuse. Glia 60, 948-964. doi:10.1002/glia.22327

Alfonso-Loeches, S., Ureña-Peralta, J., Morillo-Bargues, M.J., Gómez-Pinedo, U., Guerri, C., 2016. Ethanol-Induced TLR4/NLRP3 Neuroinflammatory Response in Microglial Cells Promotes Leukocyte Infiltration Across the BBB. Neurochem. Res. 41, 193-209. doi:10.1007/s11064-015$1760-5$

Allan, A.M., Chynoweth, J., Tyler, L. a, Caldwell, K.K., 2003. A mouse model of prenatal ethanol exposure using a voluntary drinking paradigm. Alcohol. Clin. Exp. Res. 27, 2009-16. doi:10.1097/01.ALC.0000100940.95053.72

Allan, A.M., Goggin, S.L., Caldwell, K.K., 2014. Prenatal alcohol exposure modifies glucocorticoid receptor subcellular distribution in the medial prefrontal cortex and impairs frontal cortexdependent learning. PLoS One 9, e96200. doi:10.1371/journal.pone.0096200

An, L., Zhang, T., 2015. Prenatal ethanol exposure impairs spatial cognition and synaptic plasticity in female rats. Alcohol 49, 581-8. doi:10.1016/j.alcohol.2015.05.004

Andersen, S.L., 2003. Trajectories of brain development: point of vulnerability or window of opportunity? Neurosci. Biobehav. Rev. 27, 3-18. doi:10.1016/S0149-7634(03)00005-8

Arai, K., Matsuki, N., Ikegaya, Y., Nishiyama, N., 2001. Deterioration of spatial learning performances in lipopolysaccharide-treated mice. Jpn. J. Pharmacol. 87, 195-201. doi:10.1254/jjp.87.195

Barbier, E., Houchi, H., Warnault, V., Pierrefiche, O., Daoust, M., Naassila, M., 2009. Effects of prenatal and postnatal maternal ethanol on offspring response to alcohol and psychostimulants in long evans rats. Neuroscience 161, 427-40. doi:10.1016/j.neuroscience.2009.03.076

Barker, G.R.I., Warburton, E.C., 2011. When Is the Hippocampus Involved in Recognition Memory? J. Neurosci. 31, 10721-10731. doi:10.1523/JNEUROSCI.6413-10.2011

Bentley, G.R., 1998. Hydration as a limiting factor in lactation. Am. J. Hum. Biol. 10, 151-161. doi:10.1002/(SICI)1520-6300(1998)10:2<151::AID-AJHB2>3.0.CO;2-O

Berman, R.F., Hannigan, J.H., 2000. Effects of prenatal alcohol exposure on the hippocampus: spatial behavior, electrophysiology, and neuroanatomy. Hippocampus 10, 94-110. doi:10.1002/(SICI)1098-1063(2000)10:1<94::AID-HIPO11>3.0.CO;2-T

Bilbo, S.D., Smith, S.H., Schwarz, J.M., 2012. A lifespan approach to neuroinflammatory and cognitive disorders: A critical role for glia. J. Neuroimmune Pharmacol. 7, 24-41. doi:10.1007/s11481-0119299-y

Bilkei-Gorzo, A., Racz, I., Valverde, O., Otto, M., Michel, K., Sastre, M., Sarstre, M., Zimmer, A., 2005. Early age-related cognitive impairment in mice lacking cannabinoid CB1 receptors. Proc. Natl. Acad. Sci. U. S. A. 102, 15670-5. doi:10.1073/pnas.0504640102 
Boehm, S.L., Moore, E.M., Walsh, C.D., Gross, C.D., Cavelli, A.M., Gigante, E., Linsenbardt, D.N., 2008. Using drinking in the dark to model prenatal binge-like exposure to ethanol in C57BL/6J mice. Dev. Psychobiol. 50, 566-78. doi:10.1002/dev.20320

Boschen, K.E., Ruggiero, M.J., Klintsova, A.Y., 2016. Neonatal binge alcohol exposure increases microglial activation in the developing rat hippocampus. Neuroscience $324,355-366$. doi:10.1016/j.neuroscience.2016.03.033

Brady, M.L., Allan, A.M., Caldwell, K.K., 2012. A limited access mouse model of prenatal alcohol exposure that produces long-lasting deficits in hippocampal-dependent learning and memory. Alcohol. Clin. Exp. Res. 36, 457-66. doi:10.1111/j.1530-0277.2011.01644.x

Breslow, R. a, Falk, D.E., Fein, S.B., Grummer-Strawn, L.M., 2007. Alcohol consumption among breastfeeding women. Breastfeed. Med. 2, 152-7. doi:10.1089/bfm.2007.0012

Burd, L., Blair, J., Dropps, K., 2012. Prenatal alcohol exposure, blood alcohol concentrations and alcohol elimination rates for the mother, fetus and newborn. J. Perinatol. 32, 652-659. doi:10.1038/jp.2012.57

CDC, 2016. Data \& Statistics | FASD | NCBDDD | CDC [WWW Document]. URL http://www.cdc.gov/ncbddd/fasd/data.html

Cebolla, A.M., Cheron, G., Hourez, R., Bearzatto, B., Dan, B., Servais, L., 2009. Effects of maternal alcohol consumption during breastfeeding on motor and cerebellar Purkinje cells behavior in mice. Neurosci. Lett. 455, 4-7. doi:10.1016/j.neulet.2009.03.034

Chappell, T.D., Margret, C.P., Li, C.X., Waters, R.S., 2007. Long-term effects of prenatal alcohol exposure on the size of the whisker representation in juvenile and adult rat barrel cortex. Alcohol 41, 239-51. doi:10.1016/j.alcohol.2007.03.005

Chastain, L.G., Sarkar, D.K., 2014. Role of microglia in regulation of ethanol neurotoxic action. Int. Rev. Neurobiol. 118, 81-103. doi:10.1016/B978-0-12-801284-0.00004-X

Choi, I.Y., Allan, A.M., Cunningham, L.A., 2005. Moderate Fetal Alcohol Exposure Impairs the Neurogenic Response to an Enriched Environment in Adult Mice. Alcohol. Clin. Exp. Res. 29, 2053-2062. doi:10.1097/01.alc.0000187037.02670.59

Clarke, M.E., Gibbard, W.B., 2003. Overview of fetal alcohol spectrum disorders for mental health professionals. Can. Child Adolesc. Psychiatr. Rev. 12, 57-63.

Comeau, W.L., Winstanley, C.A., Weinberg, J., 2014. Prenatal alcohol exposure and adolescent stress unmasking persistent attentional deficits in rats. Eur. J. Neurosci. 40, 3078-3095. doi:10.1111/ejn.12671

Connor, P.D., Sampson, P.D., Streissguth, A.P., Bookstein, F.L., Barr, H.M., 2006. Effects of prenatal alcohol exposure on fine motor coordination and balance: A study of two adult samples. Neuropsychologia 44, 744-751. doi:10.1016/j.neuropsychologia.2005.07.016

Crabbe, J.C., Harris, R.A., Koob, G.F., 2011. Preclinical studies of alcohol binge drinking. Ann. N. Y. Acad. Sci. 1216, 24-40. doi:10.1111/j.1749-6632.2010.05895.x

Crews, F.T., Sarkar, D.K., Qin, L., Zou, J., Boyadjieva, N., Vetreno, R.P., 2015. Neuroimmune Function and the Consequences of Alcohol Exposure. Alcohol Res. 37, 331-41, 344-51.

Crews, F.T., Vetreno, R.P., 2014. Neuroimmune basis of alcoholic brain damage. Int. Rev. Neurobiol. 118, 315-57. doi:10.1016/B978-0-12-801284-0.00010-5

Cullen, C.L., Burne, T.H., Lavidis, N. a, Moritz, K.M., 2014. Low dose prenatal alcohol exposure does not impair spatial learning and memory in two tests in adult and aged rats. PLoS One 9, e101482. doi:10.1371/journal.pone.0101482

Dasgupta, S., Adams, J. a, Hogan, E.L., 2007. Maternal alcohol consumption increases sphingosine levels in the brains of progeny mice. Neurochem. Res. 32, 2217-24. doi:10.1007/s11064-007-9445-3 
Dörrie, N., Föcker, M., Freunscht, I., Hebebrand, J., 2014. Fetal alcohol spectrum disorders. Eur. Child Adolesc. Psychiatry 23, 863-75. doi:10.1007/s00787-014-0571-6

Drew, P.D., Kane, C.J.M., 2014. Fetal alcohol spectrum disorders and neuroimmune changes. Int. Rev. Neurobiol. 118, 41-80. doi:10.1016/B978-0-12-801284-0.00003-8

Dursun, I., Jakubowskadogru, E., Uzbay, T., 2006. Effects of prenatal exposure to alcohol on activity, anxiety, motor coordination, and memory in young adult Wistar rats. Pharmacol. Biochem. Behav. 85, 345-355. doi:10.1016/j.pbb.2006.09.001

El Shawa, H., Abbott, C.W., Huffman, K.J., 2013. Prenatal ethanol exposure disrupts intraneocortical circuitry, cortical gene expression, and behavior in a mouse model of FASD. J. Neurosci. 33, 18893-905. doi:10.1523/JNEUROSCI.3721-13.2013

Emery, B., Agalliu, D., Cahoy, J.D., Watkins, T.A., Dugas, J.C., Mulinyawe, S.B., Ibrahim, A., Ligon, K.L., Rowitch, D.H., Barres, B.A., 2009. Myelin Gene Regulatory Factor Is a Critical Transcriptional Regulator Required for CNS Myelination. Cell 138, 172-185. doi:10.1016/j.cell.2009.04.031

Esteve-Arenys, A., Gracia-Rubio, I., Cantacorps, L., Pozo, O.J., Marcos, J., Rodríguez-Árias, M., Miñarro, J., Valverde, O., 2017. Binge ethanol drinking during adolescence modifies cocaine responses in mice. J. Psychopharmacol. 31, 86-95. doi:10.1177/0269881116681457

Fan, J., Jacobson, S.W., Taylor, P.A., Molteno, C.D., Dodge, N.C., Stanton, M.E., Jacobson, J.L., Meintjes, E.M., 2016. White matter deficits mediate effects of prenatal alcohol exposure on cognitive development in childhood. Hum. Brain Mapp. 37, 2943-2958. doi:10.1002/hbm.23218

Farrelly, L., Föcking, M., Piontkewitz, Y., Dicker, P., English, J., Wynne, K., Cannon, M., Cagney, G., Cotter, D.R., 2015. Maternal immune activation induces changes in myelin and metabolic proteins, some of which can be prevented with risperidone in adolescence. Dev. Neurosci. 37, 43-55. doi:10.1159/000368305

Fernandez-Lizarbe, S., Montesinos, J., Guerri, C., 2013. Ethanol induces TLR4/TLR2 association, triggering an inflammatory response in microglial cells. J. Neurochem. 126, 261-73. doi:10.1111/jnc.12276

Fernandez-Lizarbe, S., Pascual, M., Guerri, C., 2009. Critical role of TLR4 response in the activation of microglia induced by ethanol. J. Immunol. 183, 4733-44. doi:10.4049/jimmunol.0803590

Flak, A.L., Su, S., Bertrand, J., Denny, C.H., Kesmodel, U.S., Cogswell, M.E., 2014. The Association of Mild, Moderate, and Binge Prenatal Alcohol Exposure and Child Neuropsychological Outcomes: A Meta-Analysis. Alcohol. Clin. Exp. Res. 38, 214-226. doi:10.1111/acer.12214

Fontaine, C.J., Patten, A.R., Sickmann, H.M., Helfer, J.L., Christie, B.R., 2016. Effects of pre-natal alcohol exposure on hippocampal synaptic plasticity: Sex, age and methodological considerations. Neurosci. Biobehav. Rev. 64, 12-34. doi:10.1016/j.neubiorev.2016.02.014

Gil-Mohapel, J., Boehme, F., Kainer, L., Christie, B.R., 2010. Hippocampal cell loss and neurogenesis after fetal alcohol exposure: Insights from different rodent models. Brain Res. Rev. doi:10.1016/j.brainresrev.2010.04.011

Glass, C.K., Saijo, K., Winner, B., Marchetto, M.C., Gage, F.H., 2010. Mechanisms Underlying Inflammation in Neurodegeneration. Cell 140, 918-934. doi:10.1016/j.cell.2010.02.016

Guerri, C., Bazinet, A., Riley, E.P., 2009. Foetal Alcohol Spectrum Disorders and alterations in brain and behaviour. Alcohol Alcohol 44, 108-14. doi:10.1093/alcalc/agn105

Guerri, C., Sanchis, R., 1986. Alcohol and acetaldehyde in rat's milk following ethanol administration. Life Sci. 38, 1543-56.

Guizzetti, M., Zhang, X., Goeke, C., Gavin, D.P., 2014. Glia and neurodevelopment: focus on fetal alcohol spectrum disorders. Front. Pediatr. 2, 123. doi:10.3389/fped.2014.00123 
Haastrup, M.B., Pottegård, A., Damkier, P., 2014. Alcohol and Breastfeeding. Basic Clin. Pharmacol. Toxicol. 114, 168-173. doi:10.1111/bcpt.12149

Hagberg, H., Gressens, P., Mallard, C., 2012. Inflammation during fetal and neonatal life: implications for neurologic and neuropsychiatric disease in children and adults. Ann. Neurol. 71, 444-57. doi:10.1002/ana.22620

Hagberg, H., Mallard, C., Ferriero, D.M., Vannucci, S.J., Levison, S.W., Vexler, Z.S., Gressens, P., 2015. The role of inflammation in perinatal brain injury. Nat. Rev. Neurol. 11, 192-208. doi:10.1038/nrneurol.2015.13

Hausknecht, K., Haj-Dahmane, S., Shen, Y.-L., Vezina, P., Dlugos, C., Shen, R.-Y., 2014. Excitatory Synaptic Function and Plasticity Is Persistently Altered in Ventral Tegmental Area Dopamine Neurons after Prenatal Ethanol Exposure. Neuropsychopharmacology 40, 893-905. doi:10.1038/npp.2014.265

Helfer, J.L., White, E.R., Christie, B.R., 2014. Prenatal Ethanol (EtOH) Exposure Alters the Sensitivity of the Adult Dentate Gyrus to Acute EtOH Exposure. Alcohol. Clin. Exp. Res. 38, 135-143. doi:10.1111/acer.12227

Heneka, M.T., Kummer, M.P., Latz, E., 2014. Innate immune activation in neurodegenerative disease. Nat. Rev. Immunol. 14, 463-477. doi:10.1038/nri3705

Ikonomidou, C., Price, M.T., Stefovska, V., Ho, F., 2000. Ethanol-Induced Apoptotic Neurodegeneration and Fetal Alcohol Syndrome. Science (80-. ). 287, 1056-1060. doi:10.1126/science.287.5455.1056

Jacobson, J.L., Jacobson, S.W., 2002. Effects of prenatal alcohol exposure on child development. Alcohol Res. Health 26, 282-6.

Jacobson, S.W., 1997. Assessing the impact of maternal drinking during and after pregnancy. Alcohol Health Res. World 21, 199-203.

Jones, K.L., Smith, D.W., 1973. Recognition of the fetal alcohol syndrome in early infancy. Lancet (London, England) 302, 999-1001.

Kleiber, M.L., Wright, E., Singh, S.M., 2011. Maternal voluntary drinking in C57BL/6J mice: Advancing a model for fetal alcohol spectrum disorders. Behav. Brain Res. 223, 376-387. doi:10.1016/j.bbr.2011.05.005

Kuhn, P.L., Petroulakis, E., Zazanis, G. a., McKinnon, R.D., 1995. Motor function analysis of myelin mutant mice using a rotarod. Int. J. Dev. Neurosci. 13, 715-722. doi:10.1016/0736-5748(96)812159

Lalonde, R., 2002. The neurobiological basis of spontaneous alternation. Neurosci. Biobehav. Rev. 26, 91-104. doi:10.1016/S0149-7634(01)00041-0

Larkby, C., Day, N., Words, E.Y., 1997. The effects of prenatal alcohol exposure. Alcohol Health Res. World 21, 192-8. doi:10.1007/s11065-011-9168-8

Lehnardt, S., 2010. Innate immunity and neuroinflammation in the CNS: The role of microglia in toll-like receptor-mediated neuronal injury. Glia 58, 253-263. doi:10.1002/glia.20928

Lippai, D., Bala, S., Petrasek, J., Csak, T., Levin, I., Kurt-Jones, E. a, Szabo, G., 2013. Alcohol-induced IL-1 $\beta$ in the brain is mediated by NLRP3/ASC inflammasome activation that amplifies neuroinflammation. J. Leukoc. Biol. 94, 171-82. doi:10.1189/jlb.1212659

Lucas, B.R., Latimer, J., Pinto, R.Z., Ferreira, M.L., Doney, R., Lau, M., Jones, T., Dries, D., Elliott, E.J., 2014. Gross motor deficits in children prenatally exposed to alcohol: a meta-analysis. Pediatrics 134, e192-209. doi:10.1542/peds.2013-3733

Maccarrone, M., Valverde, O., Barbaccia, M.L., Castañé, A., Maldonado, R., Ledent, C., Parmentier, M., Finazzi-Agrò, A., 2002. Age-related changes of anandamide metabolism in CB1 cannabinoid receptor knockout mice: correlation with behaviour. Eur. J. Neurosci. 15, 1178-86. 
Makinodan, M., Tatsumi, K., Manabe, T., Yamauchi, T., Makinodan, E., Matsuyoshi, H., Shimoda, S., Noriyama, Y., Kishinioto, T., Wanaka, A., 2008. Maternal immune activation in mice delays myelination and axonal development in the hippocampus of the offspring. J. Neurosci. Res. 86, 2190-2200. doi:10.1002/jnr.21673

Marquardt, K., Brigman, J.L., 2016. The impact of prenatal alcohol exposure on social, cognitive and affective behavioral domains: Insights from rodent models. Alcohol 51, 1-15. doi:10.1016/j.alcohol.2015.12.002

Marquardt, K., Sigdel, R., Caldwell, K., Brigman, J.L., 2014. Prenatal ethanol exposure impairs executive function in mice into adulthood. Alcohol. Clin. Exp. Res. 38, 2962-8. doi:10.1111/acer.12577

May, P.A., Baete, A., Russo, J., Elliott, A.J., Blankenship, J., Kalberg, W.O., Buckley, D., Brooks, M., Hasken, J., Abdul-Rahman, O., Adam, M.P., Robinson, L.K., Manning, M., Hoyme, H.E., 2014. Prevalence and Characteristics of Fetal Alcohol Spectrum Disorders. Pediatrics 134, 855-866. doi:10.1542/peds.2013-3319

McKenzie, I.A., Ohayon, D., Li, H., de Faria, J.P., Emery, B., Tohyama, K., Richardson, W.D., 2014. Motor skill learning requires active central myelination. Science 346, 318-22. doi: $10.1126 /$ science. 1254960

Mennella, J., 2001. Alcohol's effect on lactation. Alcohol Res. Health 25, 230-4.

Mitew, S., Hay, C.M., Peckham, H., Xiao, J., Koenning, M., Emery, B., 2014. Mechanisms regulating the development of oligodendrocytes and central nervous system myelin. Neuroscience 276, 29-47. doi:10.1016/j.neuroscience.2013.11.029

Montesinos, J., Alfonso-Loeches, S., Guerri, C., 2016. Impact of the Innate Immune Response in the Actions of Ethanol on the Central Nervous System. Alcohol. Clin. Exp. Res. 1-11. doi:10.1111/acer. 13208

Montesinos, J., Pascual, M., Pla, A., Maldonado, C., Rodríguez-Arias, M., Miñarro, J., Guerri, C., 2015. TLR4 elimination prevents synaptic and myelin alterations and long-term cognitive dysfunctions in adolescent mice with intermittent ethanol treatment. Brain. Behav. Immun. 45, 233-44. doi:10.1016/j.bbi.2014.11.015

Moscoso-Castro, M., Gracia-Rubio, I., Ciruela, F., Valverde, O., 2016. Genetic blockade of adenosine A2A receptors induces cognitive impairments and anatomical changes related to psychotic symptoms in mice. Eur. Neuropsychopharmacol. 1-14. doi:10.1016/j.euroneuro.2016.04.003

Most, D., Ferguson, L., Harris, R.A., 2014. Molecular basis of alcoholism. Handb. Clin. Neurol. 125, 89111. doi:10.1016/B978-0-444-62619-6.00006-9

National Institute on Alcohol Abuse and Alcoholism (NIAAA), 2016. Drinking levels defined [WWW Document]. URL https://www.niaaa.nih.gov/alcohol-health/overview-alcoholconsumption/moderate-binge-drinking

Olney, J.W., Tenkova, T., Dikranian, K., Muglia, L.J., Jermakowicz, W.J., D’Sa, C., Roth, K.A., 2002 a. Ethanol-induced caspase-3 activation in the in vivo developing mouse brain. Neurobiol. Dis. 9, 205-19. doi:10.1006/nbdi.2001.0475

Olney, J.W., Tenkova, T., Dikranian, K., Qin, Y.-Q., Labruyere, J., Ikonomidou, C., 2002b. Ethanolinduced apoptotic neurodegeneration in the developing C57BL/6 mouse brain. Dev. Brain Res. 133, 115-126. doi:10.1016/S0165-3806(02)00279-1

Patten, A.R., Fontaine, C.J., Christie, B.R., 2014. A comparison of the different animal models of fetal alcohol spectrum disorders and their use in studying complex behaviors. Front. Pediatr. 2, 93. doi:10.3389/fped.2014.00093

Popović, M., Caballero-Bleda, M., Guerri, C., 2006. Adult rat's offspring of alcoholic mothers are impaired on spatial learning and object recognition in the Can test. Behav. Brain Res. 174, 101-11. doi:10.1016/j.bbr.2006.07.012 
Rhodes, J.S., Best, K., Belknap, J.K., Finn, D. a, Crabbe, J.C., 2005. Evaluation of a simple model of ethanol drinking to intoxication in C57BL/6J mice. Physiol. Behav. 84, 53-63. doi:10.1016/j.physbeh.2004.10.007

Riley, E.P., Infante, M.A., Warren, K.R., 2011. Fetal alcohol spectrum disorders: an overview. Neuropsychol. Rev. 21, 73-80. doi:10.1007/s11065-011-9166-x

Sadrian, B., Lopez-Guzman, M., Wilson, D. a, Saito, M., 2014. Distinct neurobehavioral dysfunction based on the timing of developmental binge-like alcohol exposure. Neuroscience 280, 204-19. doi:10.1016/j.neuroscience.2014.09.008

Saito, M., Chakraborty, G., Hui, M., Masiello, K., Saito, M., 2016. Ethanol-Induced Neurodegeneration and Glial Activation in the Developing Brain. Brain Sci. 6, 31. doi:10.3390/brainsci6030031

Savage, D.D., Becher, M., de la Torre, A.J., Sutherland, R.J., 2002. Dose-dependent effects of prenatal ethanol exposure on synaptic plasticity and learning in mature offspring. Alcohol. Clin. Exp. Res. 26, 1752-1758. doi:10.1097/01.ALC.0000038265.52107.20

Scholz, J., Niibori, Y., W Frankland, P., P Lerch, J., 2015. Rotarod training in mice is associated with changes in brain structure observable with multimodal MRI. Neuroimage 107, 182-189. doi:10.1016/j.neuroimage.2014.12.003

Semple, B.D., Blomgren, K., Gimlin, K., Ferriero, D.M., Noble-Haeusslein, L.J., 2013a. Brain development in rodents and humans: Identifying benchmarks of maturation and vulnerability to injury across species. Prog. Neurobiol. 106-107, 1-16. doi:10.1016/j.pneurobio.2013.04.001

Semple, B.D., Blomgren, K., Gimlin, K., Ferriero, D.M., Noble-Haeusslein, L.J., 2013b. Brain development in rodents and humans: Identifying benchmarks of maturation and vulnerability to injury across species. Prog. Neurobiol. 106-107, 1-16. doi:10.1016/j.pneurobio.2013.04.001

Shiotsuki, H., Yoshimi, K., Shimo, Y., Funayama, M., Takamatsu, Y., Ikeda, K., Takahashi, R., Kitazawa, S., Hattori, N., 2010. A rotarod test for evaluation of motor skill learning. J. Neurosci. Methods 189, 180-185. doi:10.1016/j.jneumeth.2010.03.026

Simi, a, Tsakiri, N., Wang, P., Rothwell, N.J., 2007. Interleukin-1 and inflammatory neurodegeneration. Biochem. Soc. Trans. 35, 1122-1126. doi:10.1042/BST0351122

Sokol, R.J., Delaney-Black, V., Nordstrom, B., 2003. Fetal alcohol spectrum disorder. JAMA 290, 29969. doi:10.1001/jama.290.22.2996

Sowell, E.R., Johnson, A., Kan, E., Lu, L.H., Van Horn, J.D., Toga, A.W., O’Connor, M.J., Bookheimer, S.Y., 2008. Mapping white matter integrity and neurobehavioral correlates in children with fetal alcohol spectrum disorders. J Neurosci 28, 1313-1319. doi:28/6/1313 [pii] \r10.1523/JNEUROSCI.5067-07.2008

Sprow, G.M., Thiele, T.E., 2012. The neurobiology of binge-like ethanol drinking: evidence from rodent models. Physiol. Behav. 106, 325-31. doi:10.1016/j.physbeh.2011.12.026

Terasaki, L.S., Schwarz, J.M., 2016. Effects of Moderate Prenatal Alcohol Exposure during Early Gestation in Rats on Inflammation across the Maternal-Fetal-Immune Interface and Later-Life Immune Function in the Offspring. J. Neuroimmune Pharmacol. doi:10.1007/s11481-016-9691-8

Thiele, T.E., Crabbe, J.C., Boehm, S.L., 2014. "Drinking in the dark" (DID): A simple mouse model of binge-like alcohol intake. Curr. Protoc. Neurosci. 1-17. doi:10.1002/0471142301.ns0949s68

Tong, M., Ziplow, J., Chen, W.C., Nguyen, Q.-G., Kim, C., de la Monte, S.M., 2013. Motor Function Deficits Following Chronic Prenatal Ethanol Exposure are Linked to Impairments in Insulin/IGF, Notch and Wnt Signaling in the Cerebellum. J. Diabetes Metab. 4, 238. doi:10.4172/21556156.1000238

Topper, L.A., Baculis, B.C., Valenzuela, C.F., 2015. Exposure of neonatal rats to alcohol has differential effects on neuroinflammation and neuronal survival in the cerebellum and hippocampus. J. 
Neuroinflammation 12, 160. doi:10.1186/s12974-015-0382-9

Valenzuela, C.F., Morton, R. a., Diaz, M.R., Topper, L., 2012. Does moderate drinking harm the fetal brain? Insights from animal models. Trends Neurosci. 35, 284-292. doi:10.1016/j.tins.2012.01.006

Wilhelm, C.J., Guizzetti, M., 2015. Fetal Alcohol Spectrum Disorders: An Overview from the Glia Perspective. Front. Integr. Neurosci. 9, 65. doi:10.3389/fnint.2015.00065

Yoon, T., Okada, J., Jung, M., Kim, J., 2008. Prefrontal cortex and hippocampus subserve different components of working memory in rats. Learn. Mem. 15, 97-105. doi:10.1101/1m.850808.tosample 
A)

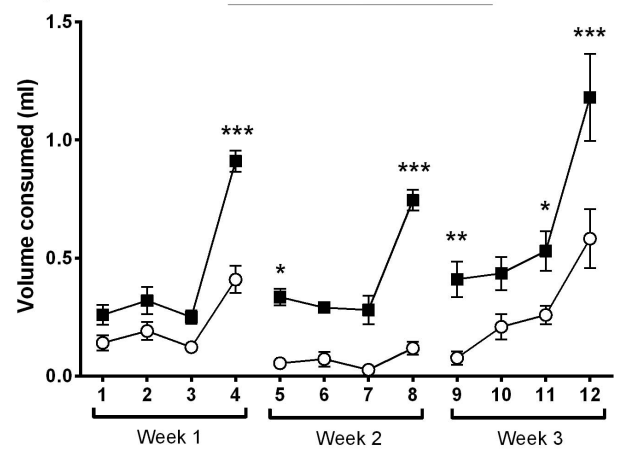

C)

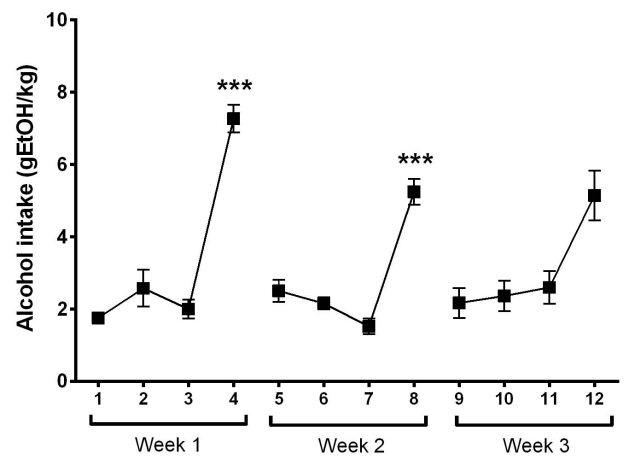

B)

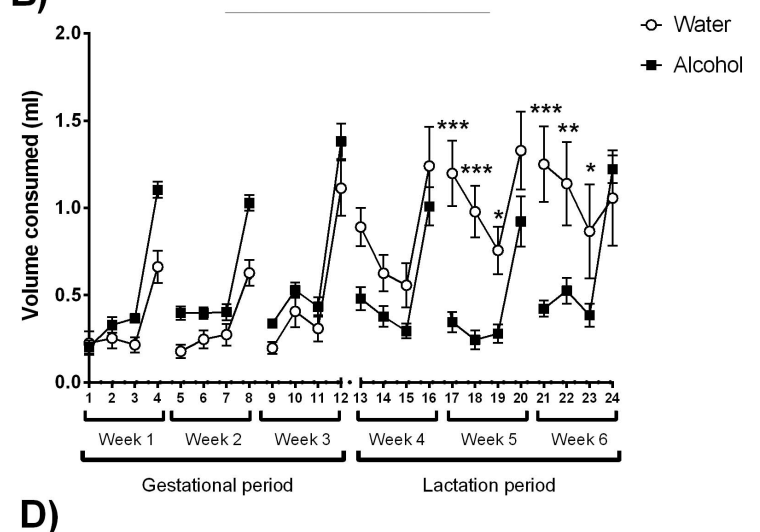

Figure 1. Maternal alcohol consumption. Volume of alcohol consumed during DID procedure throughout the prenatal period (A) or both prenatal and lactation periods (B). Alcohol was available $2 \mathrm{~h} /$ day on days 1 st to $3^{\text {rd }}$ and $4 \mathrm{~h}$ on day $4^{\text {th }}$ of the series. Two-way ANOVA and Bonferroni post-hoc test. ${ }^{*} \mathrm{p}<0.05,{ }^{* *} \mathrm{p}<0.01,{ }^{* * *} \mathrm{p}<0.001$ Water vs. Alcohol. Alcohol intake (g $\mathrm{EtOH} / \mathrm{kg}$ ) during prenatal DID test (C) or prenatal and lactation DID test (D). One-way ANOVA with repeated measures and Bonferroni post-hoc test. ${ }^{*} \mathrm{p}<0.05,{ }^{* * *} \mathrm{p}<0.0014^{\text {th }}$ day of each week compared with three previous days. Data are expressed as [mean $\pm \mathrm{SEM}$ ] $(\mathrm{n}=11$ to $16)$. 

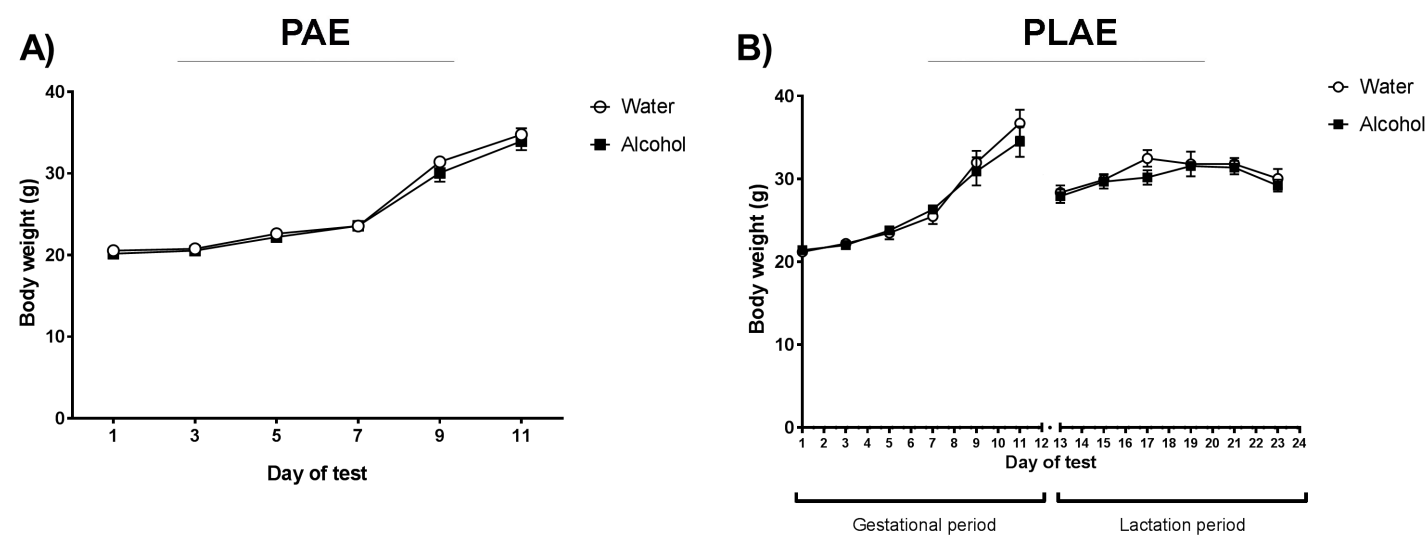

Figure 2. Maternal body weight. Body weight $[$ mean $\pm \mathrm{SEM}]$ of mothers was measured during DID procedure throughout the prenatal period (A) (n=14-16 per group) or both prenatal and lactation periods (B) ( $\mathrm{n}=6-8$ per group) at 2-day intervals. Two-way ANOVA and Bonferroni post-hoc test (n.s.). 
BAC vs. Volume

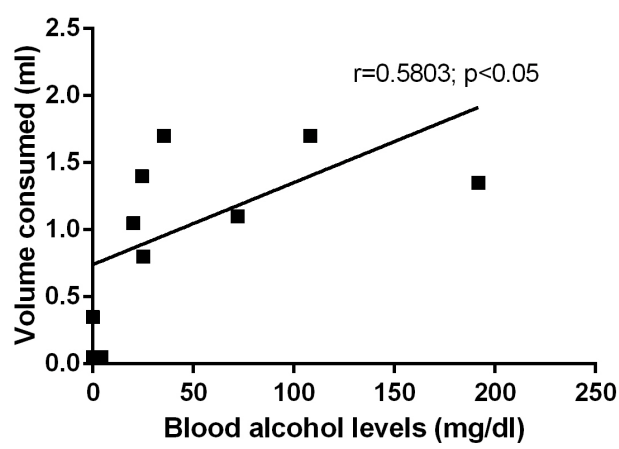

BAC vs. Intake

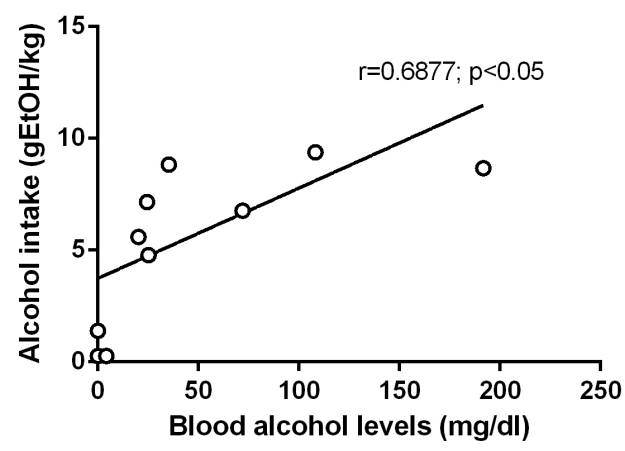

Figure 3. Correlations between blood alcohol concentration and volume consumed or alcohol intake levels after maternal binge alcohol drinking episode. BAC values obtained were compared with volume consumed and alcohol intake levels on the $12^{\text {th }}$ day. Pearson coefficient of correlation was determined for each comparison: $r=0.5803 ; \mathrm{p}<0.05$ (BAC vs. Volume) and $\mathrm{r}=0.6877 ; \mathrm{p}<0.05$ (BAC vs. Intake) $(\mathrm{n}=12)$. 

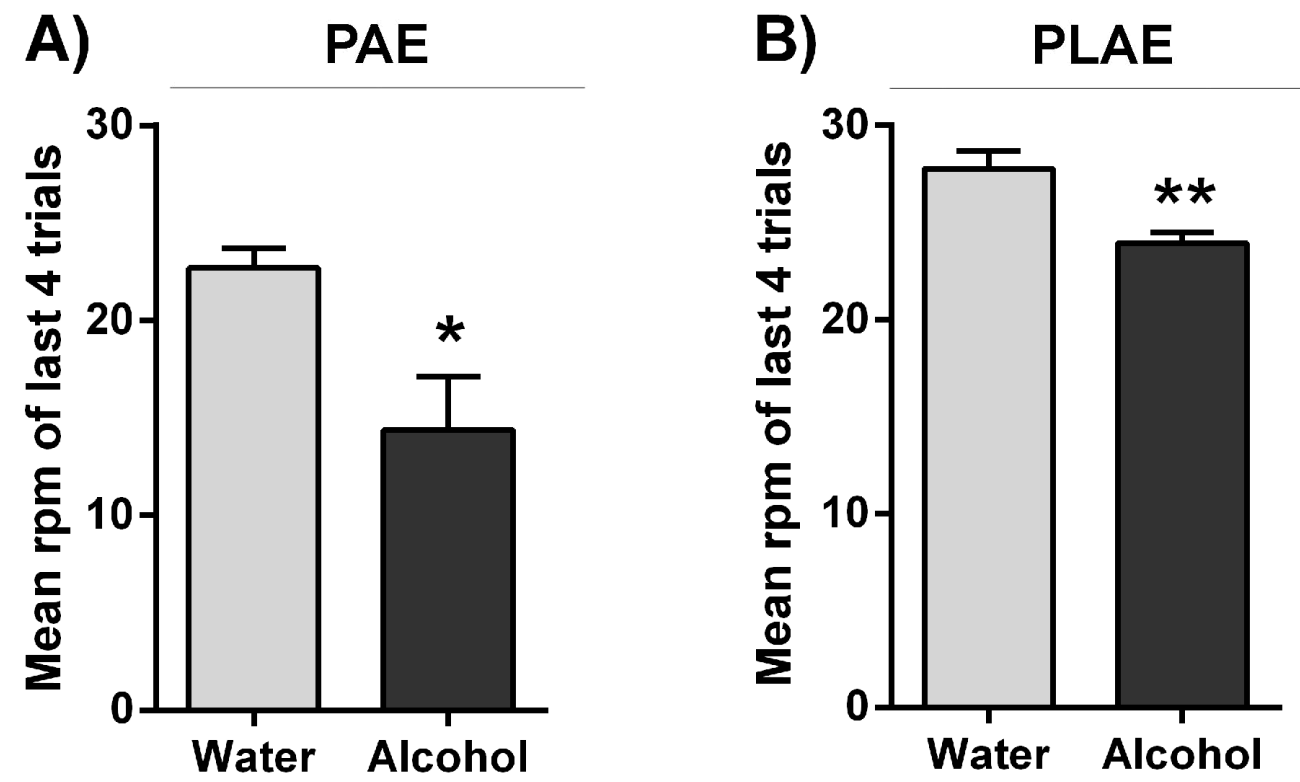

Figure 4. Deficits of motor coordination in the offspring after maternal binge alcohol consumption. Data are expressed as $[$ mean \pm SEM] of the rpm obtained in the last four trials of the rotarod test in A) PAE ( $\mathrm{n}=4$ per group) and B) PLAE mice (B) ( $\mathrm{n}=8$ per group). Student's ttest ${ }^{*} \mathrm{p}<0.05, * * \mathrm{p}<0.01$ Water vs. Alcohol. 

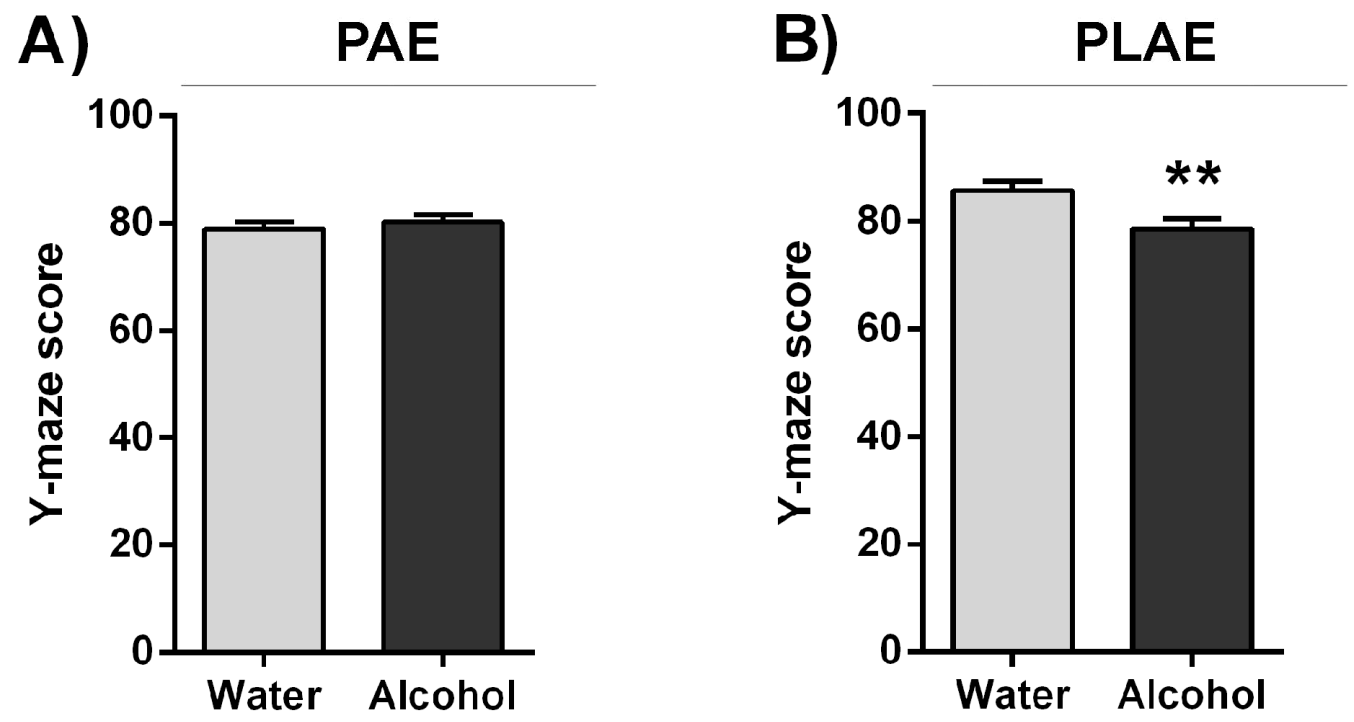

C)

D)

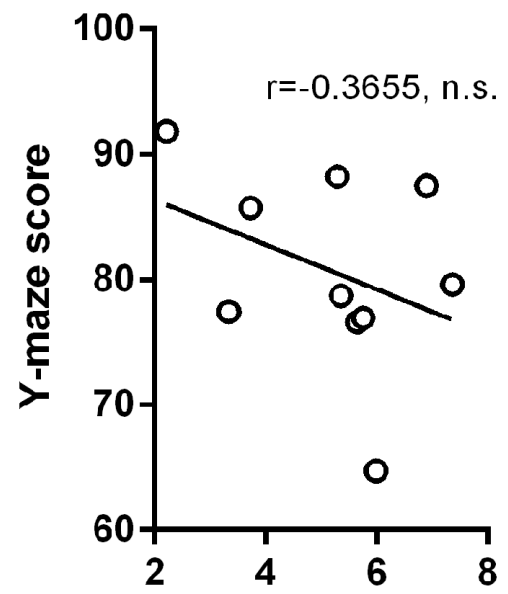

Alcohol intake $(\mathrm{gEtOH} / \mathrm{kg})$

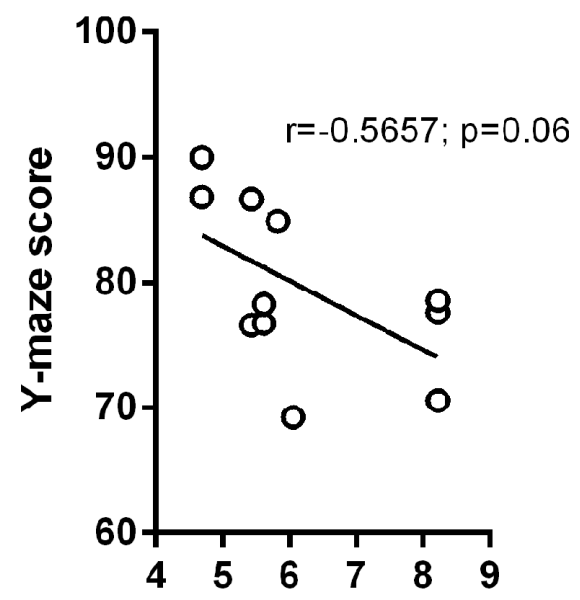

Alcohol intake (gEtOH/kg)

Figure 5. Effects of early alcohol exposure on spatial working memory in the Y-maze test and correlation between maternal alcohol intake and offspring behavioral scores. The $[$ mean $\pm \mathrm{SEM}]$ of spontaneous alternation score in A) PAE animals ( $\mathrm{n}=9-11$ per group) and in B) PLAE mice ( $\mathrm{n}=8-10$ per group). Student's t-test $* * \mathrm{p}<0.01$ Water vs. Alcohol. Pearson coefficient of correlation between score obtained in $\mathrm{Y}$-maze and maternal alcohol intake: $\mathrm{r}=0.3655$; n.s. (PAE animals; $\mathrm{C}$ ) and $\mathrm{r}=0.5657 ; \mathrm{p}=0.06$ (PLAE mice; $\mathrm{D}$ ). 

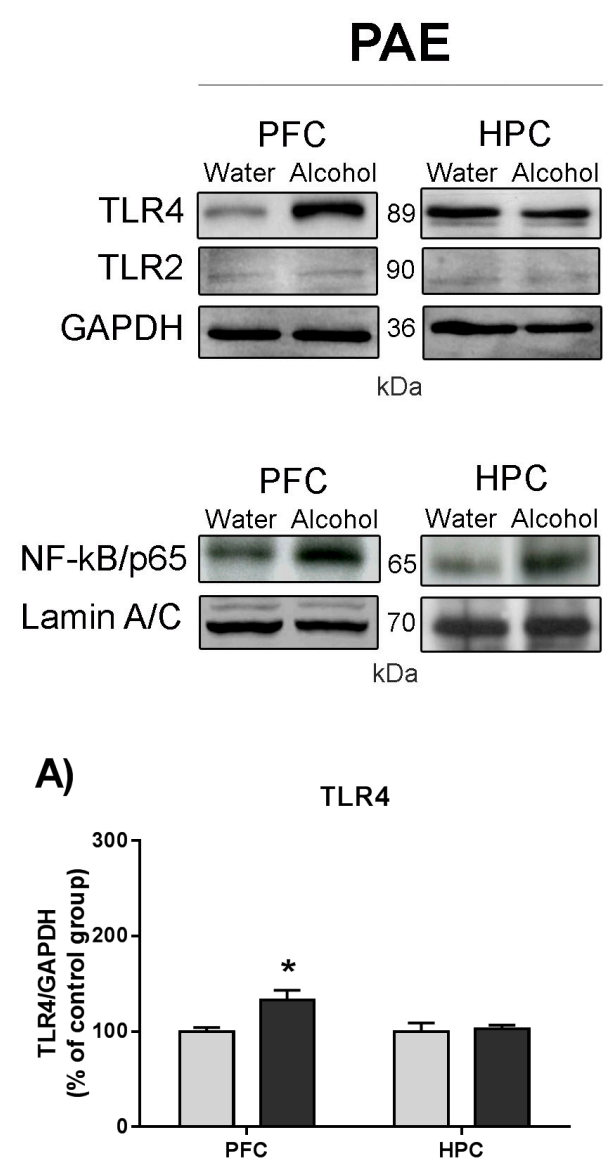

C)

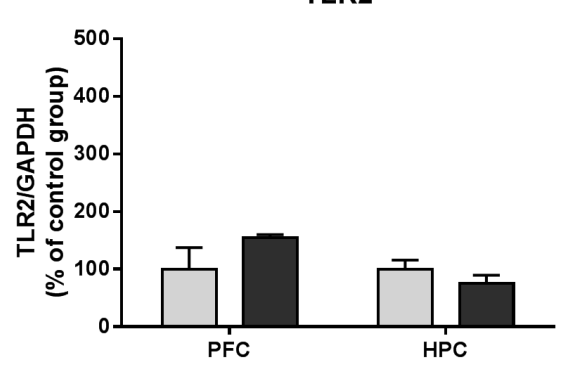

E)

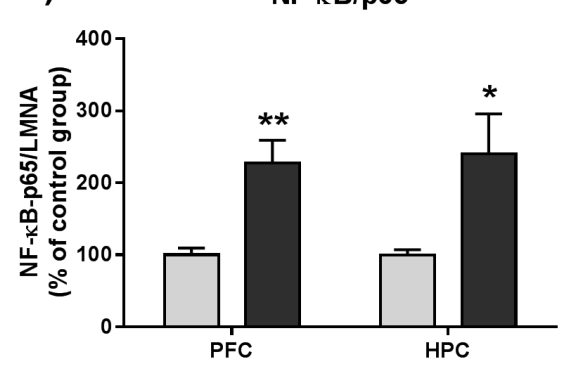

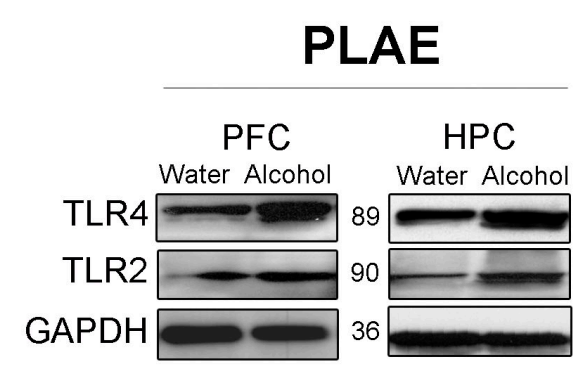

$\mathrm{kDa}$

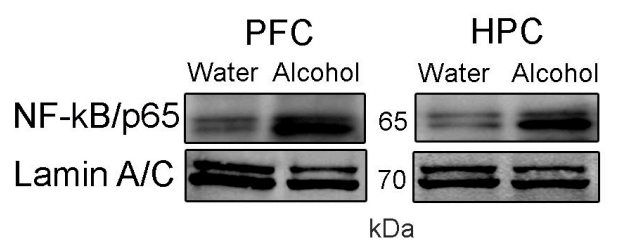

B)

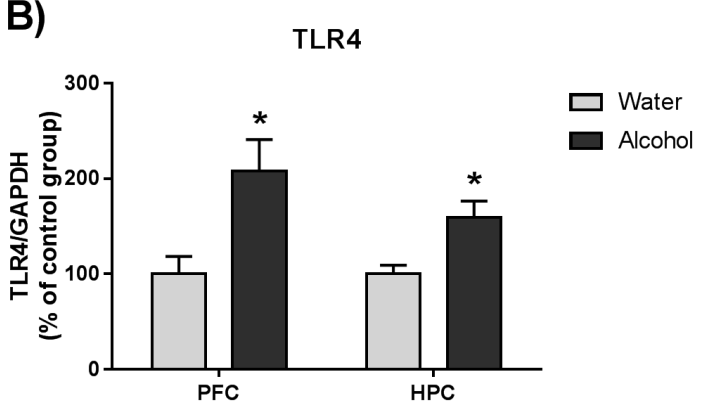

D)

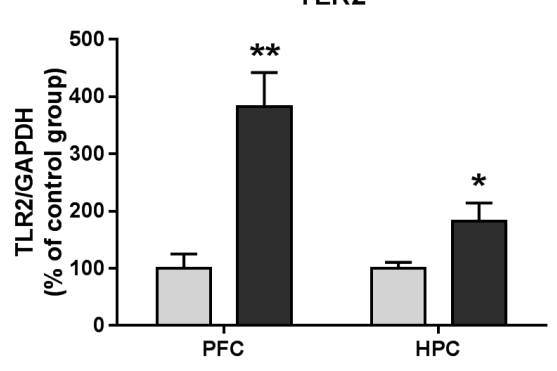

F)

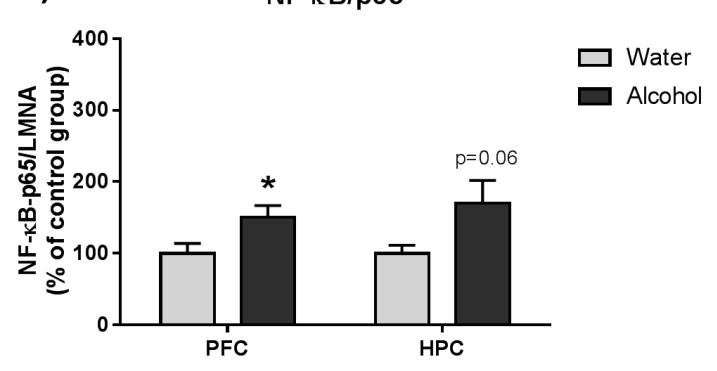

Figure 6. Persistent alterations in the neuroinflammatory pathways associated with the innate immune response due to maternal binge alcohol consumption. Western blot analysis 
of TLR4, TLR2 and NFKB/p65 was performed for each study condition in PAE animals (A, C, E) and PLAE mice (B, D, F). GAPDH and Lamin A/C were used as loading controls. A representative blot of each protein is shown. Normalized densitometry values are presented as $[$ mean $\pm \mathrm{SEM}]\left(\mathrm{n}=3-5\right.$ per group). Student's t-test ${ }^{*} \mathrm{p}<0.05,{ }^{* *} \mathrm{p}<0.01$ Water vs. Alcohol. 
PAE

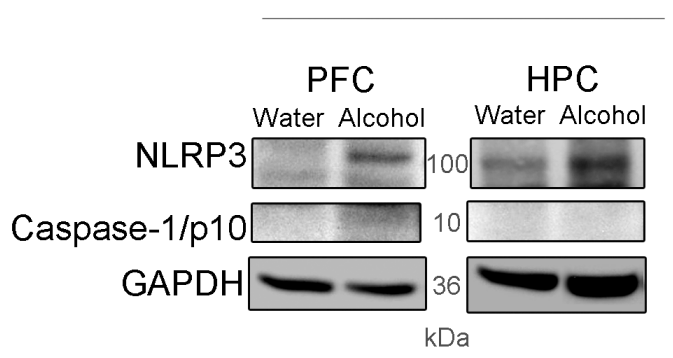

A)

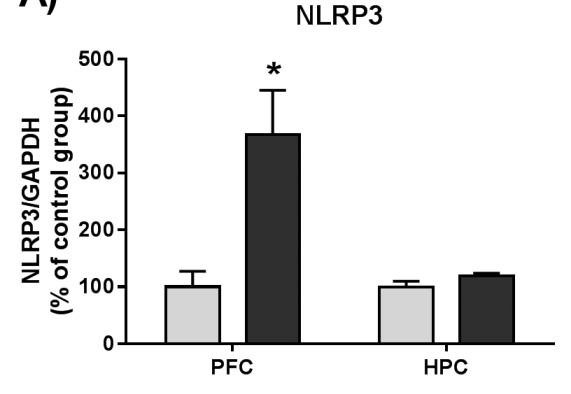

C)

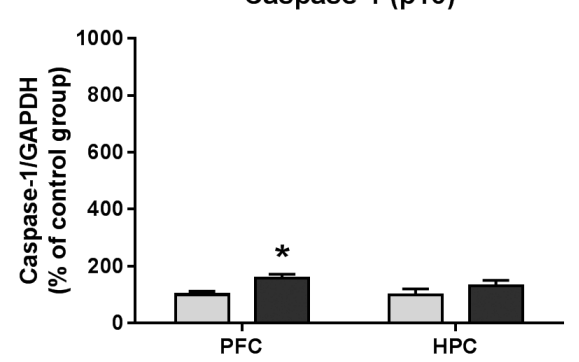

E)

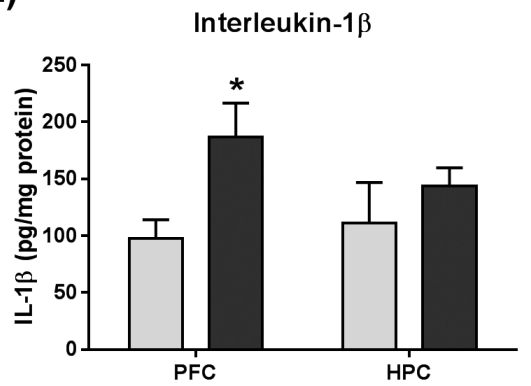

PLAE

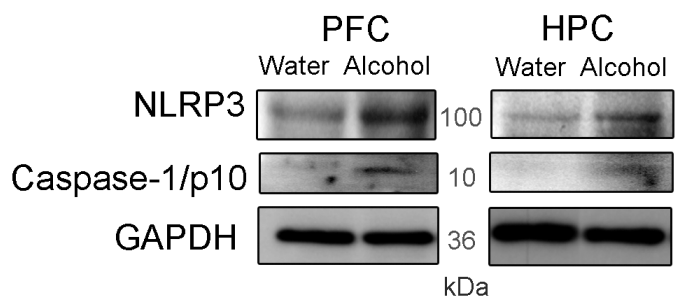

B)

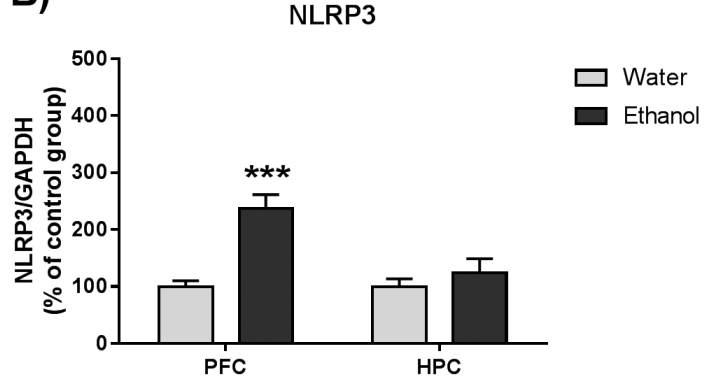

D)

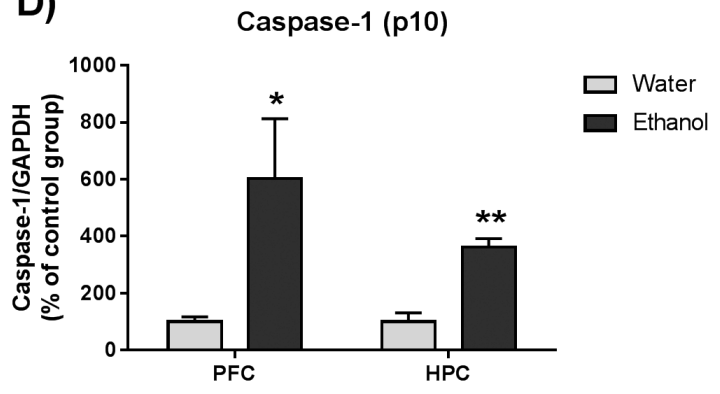

F)

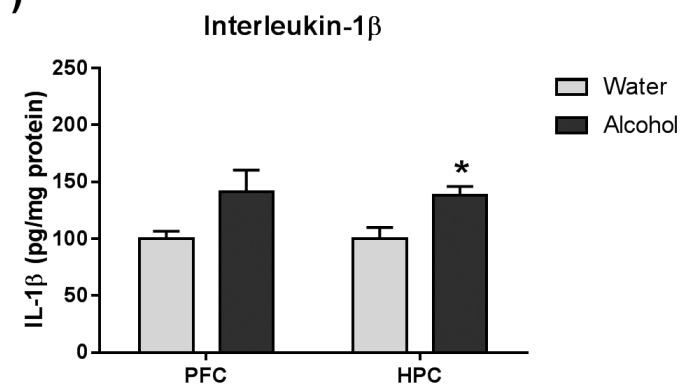

Figure 7. Persistent effects of early alcohol exposure on the expression of proinflammatory molecules. Western blot analysis of NLRP3 and caspase-1 was performed for each study condition in PAE animals (A, C) and PLAE mice (B, D). GAPDH was used as a loading control. A representative blot of each protein is shown. Normalized densitometry values are presented as [mean $\pm \mathrm{SEM}$ ] ( $\mathrm{n}=3-5$ per group). IL- $1 \beta$ cytokine levels were assessed in PAE (E) or PLAE (F) mice by using an ELISA and expressed as $\mathrm{pg} / \mathrm{mg}$ of protein [mean $\pm \mathrm{SEM}$ ] (n=3-5 per group). Student's t-test $* \mathrm{p}<0.05, * * \mathrm{p}<0.01, * * * \mathrm{p}<0.001$ Water vs. Alcohol. 


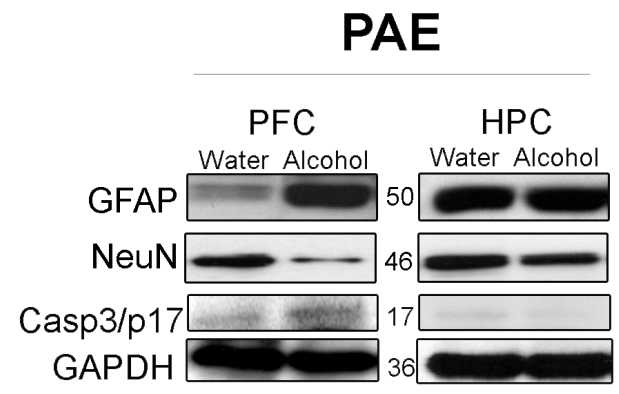

$\mathrm{kDa}$

A)

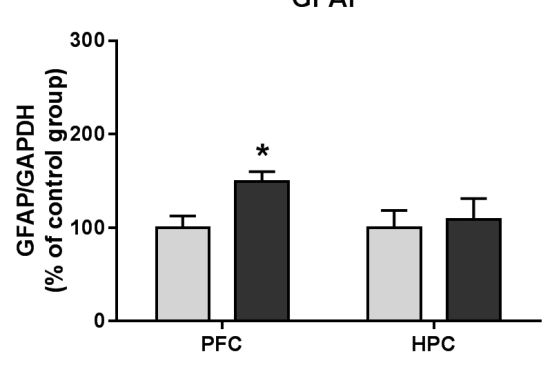

C)

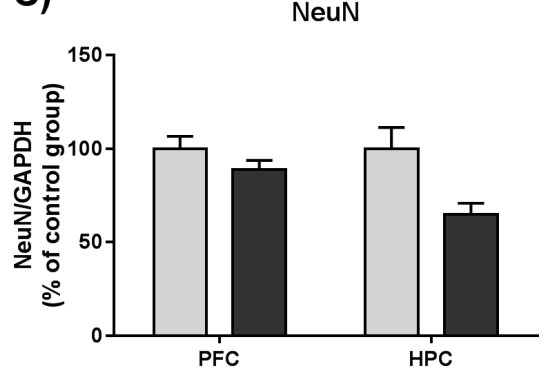

E)

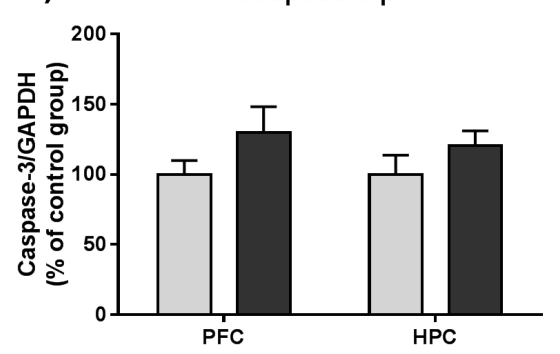

PLAE

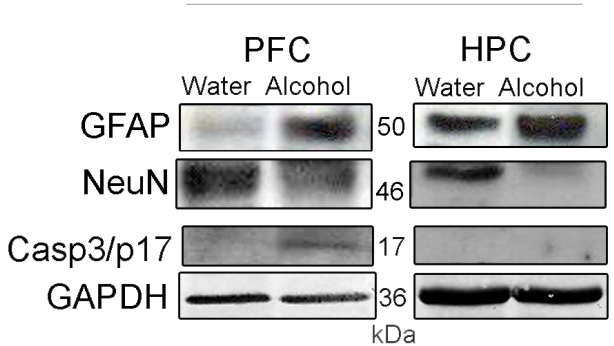

B)

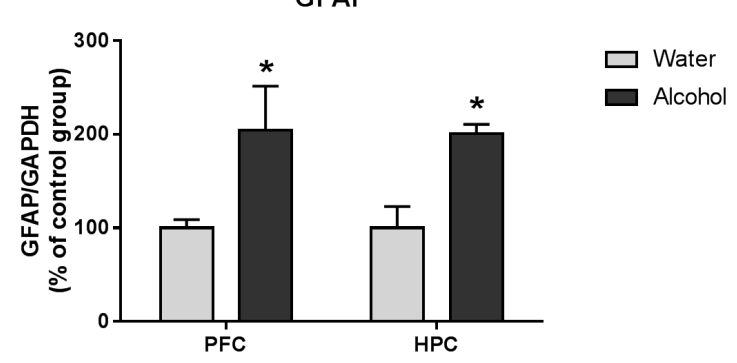

D)

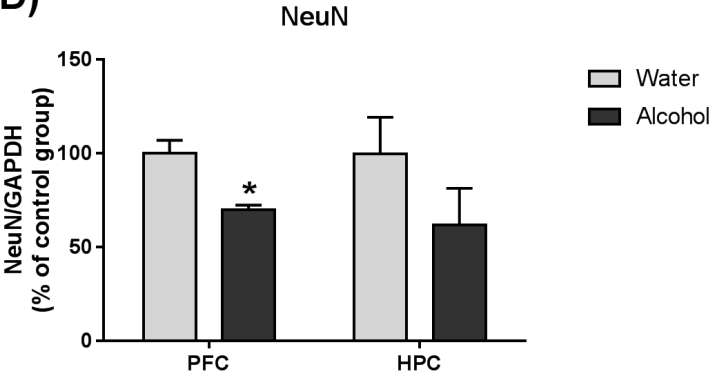

F)

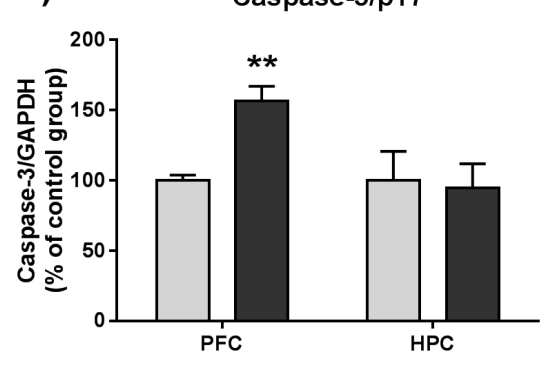

Figure 8. Effects of early alcohol exposure on glial activation and neuron cells. The expression of GFAP, NeuN and caspase-3 was analyzed in the PFC and HPC of PAE (A, C, E) and PLAE mice (B, D, F). GAPDH was used as loading control. Data are presented as [mean \pm SEM] ( $n=3-5$ per group). Student's t-test $* \mathrm{p}<0.05,{ }^{* *} \mathrm{p}<0.01$ Water vs. Alcohol. 


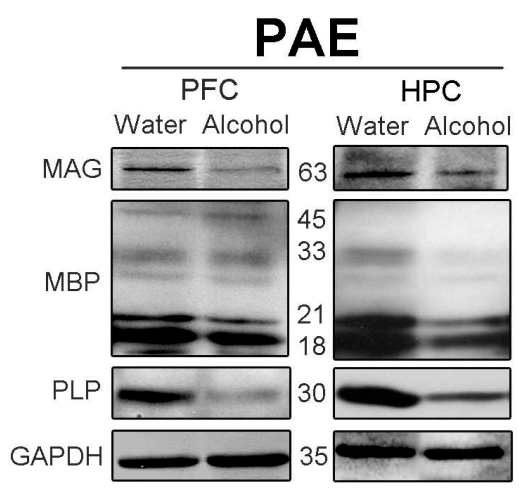

$\mathrm{kDa}$

A)

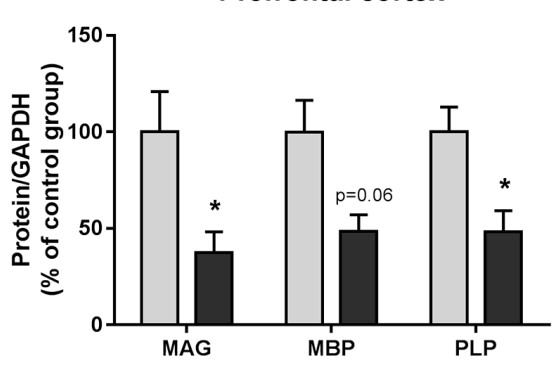

C)

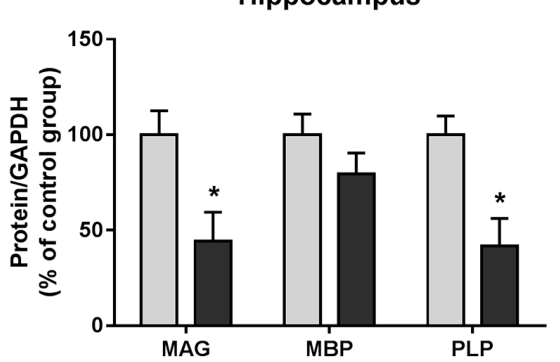

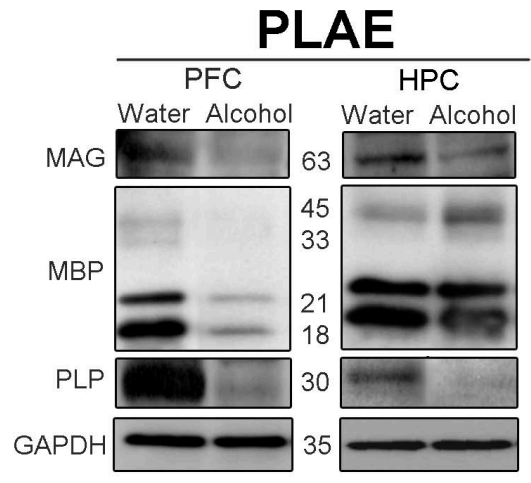

$\mathrm{kDa}$

B)

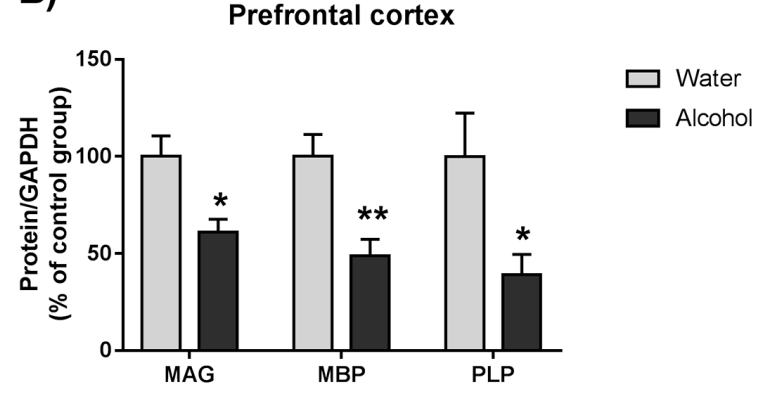

D)

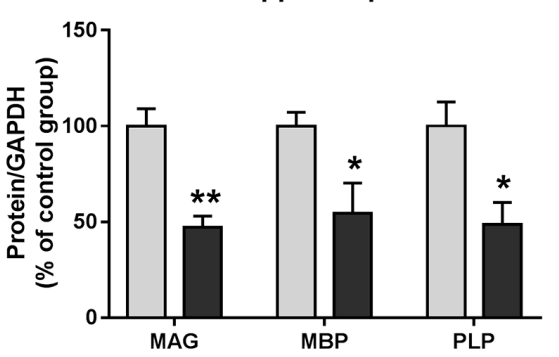

Figure 9. Persistent effects of alcohol exposure during development on myelin. The expression of MBP, PLP and MAG was analyzed in the PFC and HPC of PAE (A, C) and PLAE mice (B, D). GAPDH was used as loading control. Data are presented as [mean $\pm \mathrm{SEM}$ ] ( $\mathrm{n}=4-6$ per group). Student's t-test $* \mathrm{p}<0.05,{ }^{*} \mathrm{p}<0.01$ Water vs. Alcohol. 


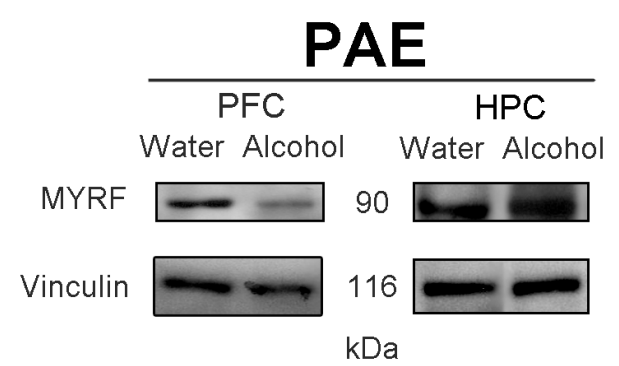

A)

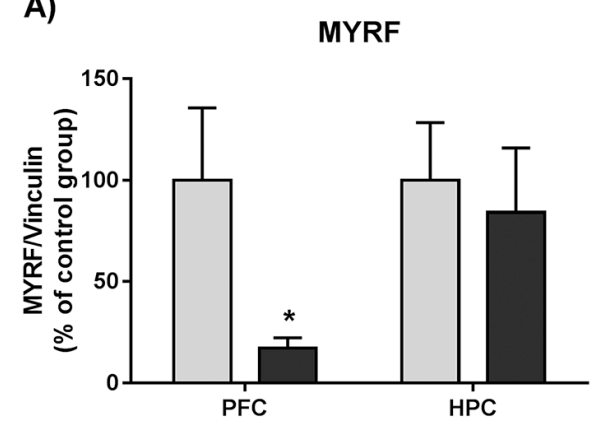

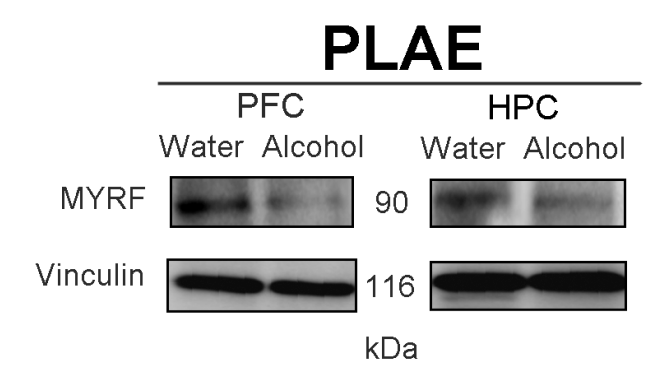

B)

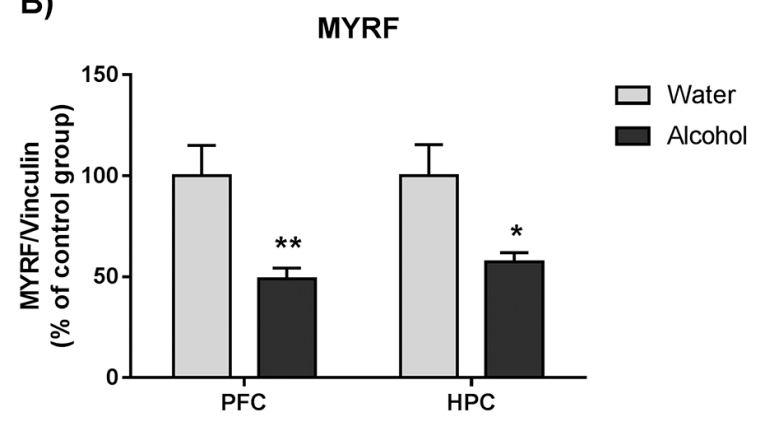

Figure 10. Effects of developmental binge-like alcohol exposure on the major myelin regulatory factor MYRF expression. The expression of MYRF was analyzed in the PFC and HPC of PAE (A) and PLAE mice (B). Vinculin was used as loading control. Data are presented as $[$ mean $\pm \mathrm{SEM}]$ ( $\mathrm{n}=3-5$ per group). Student's t-test $* \mathrm{p}<0.05,{ }^{* *} \mathrm{p}<0.01$ Water vs. Alcohol. 